\title{
Mitochondrial Dysfunction Due to Lack of Manganese Superoxide Dismutase Promotes Hepatocarcinogenesis
}

\author{
Anja Konzack, Mirza Jakupovic, ${ }^{2}$ Kateryna Kubaichuk, Agnes Görlach, ${ }^{3}$ Frank Dombrowski, ${ }^{4}$ \\ Ilkka Miinalainen, ${ }^{5}$ Raija Sormunen, ${ }^{5}$ and Thomas Kietzmann ${ }^{1}$
}

\begin{abstract}
Aims: One of the cancer hallmarks is mitochondrial dysfunction associated with oxidative stress. Among the first line of defense against oxidative stress is the dismutation of superoxide radicals, which in the mitochondria is carried out by manganese superoxide dismutase (MnSOD). Accordingly, carcinogenesis would be associated with a dysregulation in MnSOD expression. However, the association studies available so far are conflicting, and no direct proof concerning the role of MnSOD as a tumor promoter or suppressor has been provided. Therefore, we investigated the role of MnSOD in carcinogenesis by studying the effect of MnSOD deficiency in cells and in the livers of mice. Results: We found that loss of MnSOD in hepatoma cells contributed to their conversion toward a more malignant phenotype, affecting all cellular properties generally associated with metabolic transformation and tumorigenesis. In vivo, hepatocyte-specific MnSOD-deficient mice showed changed organ architecture, increased expression of tumor markers, and a faster response to carcinogenesis. Moreover, deficiency of MnSOD in both the in vitro and in vivo model reduced $\beta$-catenin and hypoxia-inducible factor- $1 \alpha$ levels. Innovation: The present study shows for the first time the important correlation between MnSOD presence and the regulation of two major pathways involved in carcinogenesis, the $\mathrm{Wnt} / \beta$-catenin and hypoxia signaling pathway. Conclusion: Our study points toward a tumor suppressive role of MnSOD in liver, where the Wnt/ $\beta$-catenin and hypoxia pathway may be crucial elements. Antioxid. Redox Signal. 23, 1059-1075.
\end{abstract}

\section{Introduction}

$\mathbf{M}$ ITOCHONDRIAL DYSFUNCTION, ONE of the hallmarks of tumor cells, is associated with an imbalance of the antioxidant defense and an increased production of reactive oxygen species (ROS) resulting in oxidative stress. Among the first line of defense against oxidative stress is the dismutation of superoxide radicals to hydrogen peroxide and molecular oxygen by superoxide dismutases (SODs); in mitochondria, this task is carried out by manganese superoxide dismutase (MnSOD).

Accordingly, carcinogenesis may be expected to be associated with a dysregulation in the expression of antioxidant enzymes such as MnSOD. Indeed, first reports showed low levels or absence of MnSOD in many tumor types $(3,47)$, whereas forced expression of MnSOD could prevent the tumorigenic phenotype in melanoma, breast cancer, and glioma cells $(8,38,57,70)$. In addition, recent studies have reported that reduced MnSOD expression in primary tongue

\footnotetext{
Innovation

The present study shows for the first time the important correlation between manganese superoxide dismutase presence and the regulation of two major pathways involved in carcinogenesis, the $\mathrm{Wnt} / \beta$-catenin and hypoxia signaling pathway.
}

\footnotetext{
${ }^{1}$ Faculty of Biochemistry and Molecular Medicine, and Biocenter Oulu, University of Oulu, Oulu, Finland.

${ }^{2}$ Department of Chemistry, University of Kaiserslautern, Kaiserslautern, Germany.

${ }^{3}$ Experimental and Molecular Pediatric Cardiology, German Heart Center Munich, Technical University Munich, Munich, Germany.

${ }^{4}$ Institute of Pathology, University of Greifswald, Greifswald, Germany.

${ }^{5}$ Biocenter Oulu Electron Microscopy Core Facility, University of Oulu, Oulu, Finland.
}

(C) Anja Konzack et al. 2015; Published by Mary Ann Liebert, Inc. This Open Access article is distributed under the terms of the Creative Commons Attribution Noncommercial License (http://creativecommons.org/licenses/by-nc/4.0/) which permits any noncommercial use, distribution, and reproduction in any medium, provided the original author(s) and the source are credited. 
squamous cell carcinoma is associated with lymph node metastasis (40). In contrast, increased levels of MnSOD were found in progressive and metastatic breast, pancreatic, gastric, colorectal prostate, and lung carcinomas $(12,42)$, and findings from mouse experiments propose that MnSOD expression switches between early and advanced stages of skin cancer (13).

Interestingly, the direct role of MnSOD in hepatocellular carcinoma has not been widely addressed, although from all organs investigated so far, MnSOD activity was shown to be highest in the liver (32). Recent studies indicate that MnSOD promoter mutations may contribute to the carcinogenic process in hepatocarcinoma cells (65), and studies in mice suggested that lack of MnSOD may affect liver development $(25,36)$, likely without affecting the integrity of mitochondrial DNA (10). Together, these findings suggest that MnSOD might be linked to a specific type and stage of cancer, but they leave open whether a lack of MnSOD in hepatocytes would be linked to a carcinogenic process. Therefore, it was the purpose of the present study to investigate whether cellular deficiency of MnSOD can promote a carcinogenic process in the liver.

Thus, we studied the effect of MnSOD deficiency in a hepatocyte-derived cell line in vitro and in vivo in the liver of mice with hepatocyte-specific lack of MnSOD. Focusing on cellular properties generally associated with metabolic transformation and tumorigenesis, we found that absence of MnSOD in the cellular model contributed to their conversion to a malignant phenotype. In line, lack of MnSOD in mouse liver strongly promoted tumor formation in a chemically induced liver carcinogenesis model. Moreover, we found that expression of the $\mathrm{Wnt} / \beta$-catenin pathway components as well as the hypoxia-inducible transcription factor (HIF-1 $\alpha$ ) was altered in both the cell as well as in the mouse model. Taken together, our study shows that lack of MnSOD exerts tumorigenic activity, which may involve the $\mathrm{Wnt} / \beta$-catenin pathway as a crucial element.

\section{Results}

\section{Loss of MnSOD results in mitochondrial} dysfunction, formation of ROS, and changes in cell morphology and enhances cell proliferation

To investigate the role of MnSOD during hepatocarcinogenesis, we generated a MnSOD-knockdown (kd) cell line from human HepG2 hepatoma cells. The kd was confirmed by Western blot analysis; no MnSOD protein could be detected in the MnSOD-kd cells in contrast to the HepG2 scrambled (HepG2-sc) cells (Fig. 1A, B). As expected, MnSOD deficiency in MnSOD-kd cells resulted in a $40 \%$ increase in dihydroethidium (DHE) fluorescence, indicating an enhanced level of superoxide (Fig. 1C, D). In addition, a 2.3-fold increase in dichlorodihydrofluorescein (DCF) fluorescence in MnSOD-kd cells indicated an enhanced level of

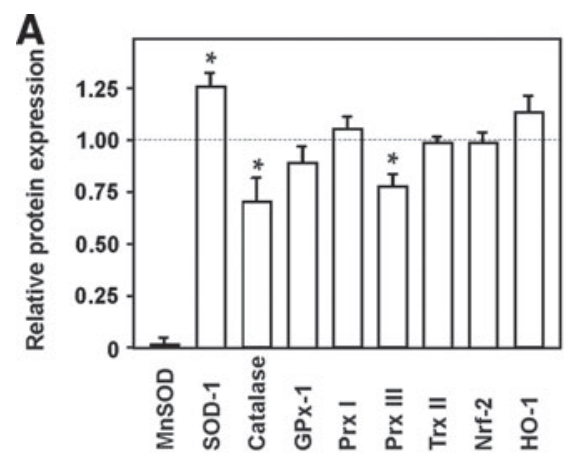

B
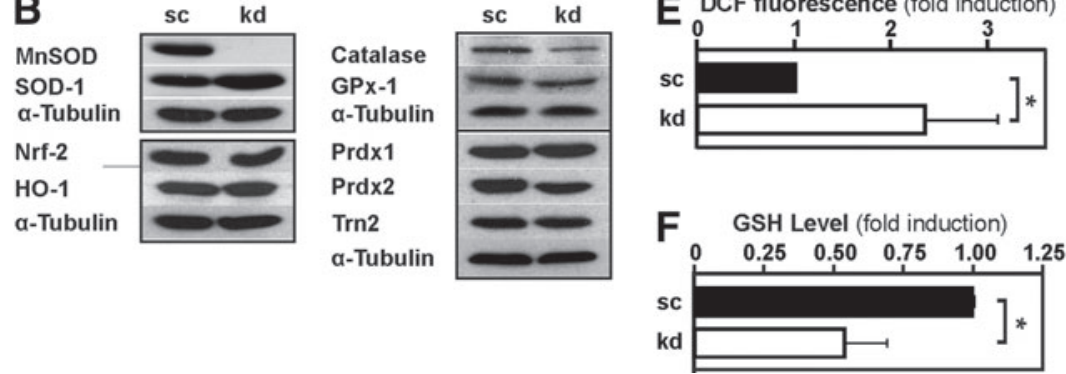

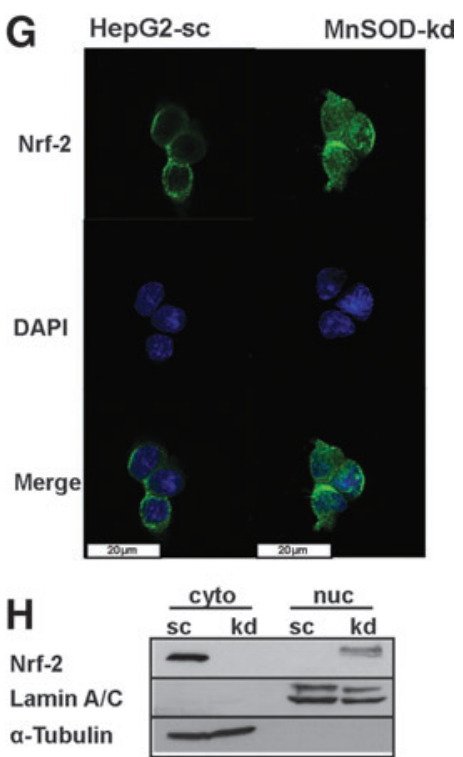

E DCF fluorescence (fold induction)

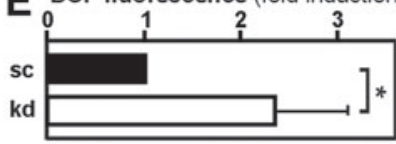

$\mathbf{C}_{\text {D }}$
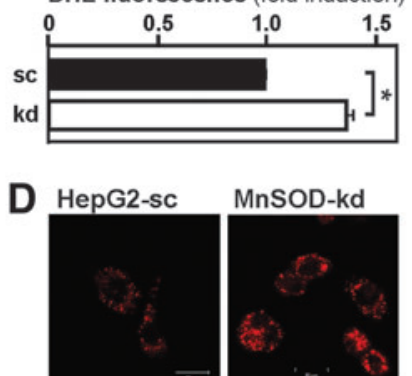

a-Tubulin

FIG. 1. Knockdown of MnSOD induces ROS levels. (A) HepG2 cells were stably transfected with a scrambled (sc) shRNA or shRNA against MnSOD (kd). Protein lysates were prepared and analyzed by Western blotting with antibodies against MnSOD, Sod-1, Catalase, GPx-1, Prdx1, Prdx3, Trn2, Nrf-2, HO-1, and $\alpha$-tubulin. Data are mean \pm SD of fold induction normalized to HepG2-sc cells $(n=3, * p<0.05)$ (B) Representative Western blots. $\alpha$-tubulin is shown for equal loading of proteins. (C-E) The redox state of HepG2-sc and MnSOD-kd cells was determined by measuring (C) DHE fluorescence $(n=3)$, (D) DHE fluorescence microscopy showing mitochondrial localization of superoxide $(n=3)$, (E) DCF fluorescence $(n=10)$, and (F) GSH levels $(n=3)$ (c.f. section "Materials and Methods"). Data are mean \pm SD of fold induction normalized to HepG2-sc $(* p<0.05)$. (G) Nrf2 localization analyzed by confocal fluorescence immunohistochemistry. (H) Representative Western blot showing Nrf2 localization after cell fractionation; Lamin A/C is shown to indicate nuclear fractions, and $\alpha$-tubulin is shown for cytosolic fraction. DCF, dichlorodihydrofluorescein; DHE, dihydroethidium; Gpx-1, glutathione peroxidase-1; GSH, reduced glutathionel; HO-1, heme oxygenase-1; kd, knockdown; MnSOD, manganese superoxide dismutase; Nrf2, NF-E2-related factor 2; Prdx, peroxiredoxin; ROS, reactive oxygen species; SD, standard deviation. To see this illustration in color, the reader is referred to the web version of this article at www.liebertpub.com/ars 
total ROS (Fig. 1E). Furthermore, the reduced glutathione (GSH) level was decreased by about $45 \%$ in MnSOD-kd cells pointing toward a more oxidized state in these cells (Fig. 1F).

To examine whether lack of MnSOD may be compensated by enhanced expression of other antioxidative enzymes, Western blot analysis for Sod-1 (Cu/ZnSOD), catalase, glutathione peroxidase-1 (Gpx-1), thioredoxin-2, and peroxiredoxin (Prdx1) and Prdx3 protein levels was performed along with determination of GSH levels. We found that only Sod-1 showed a $25 \%$ compensatory increase in the absence of MnSOD, whereas catalase and Prdx 3 levels were decreased by $30 \%$ and $20 \%$, respectively. Other proteins involved in antioxidant reactions; among them, the NF-E2-related factor 2 (Nrf2) targets heme oxygenase-1 (HO-1), Prdx1, and the master regulator of antioxidant genes Nrf2 itself were not affected by MnSOD deficiency (Fig. 1A, B).

However, since Nrf2 changes its localization in response to redox changes, we performed cytosol/nuclear fractionation assays and confocal microscopy to assess Nrf2 differences with respect to cytosolic or nuclear presence. We detected Nrf2 almost exclusively in the cytosolic fraction of the wildtype cells, whereas Nrf2 was present in the nuclear fraction of the MnSOD-kd cells; In addition, confocal microscopy revealed that Nrf2 is primarily cytoplasmic in the control cells, whereas it is found much stronger in the nucleus of MnSODkd cells (Fig. 1G, H).

To assess whether loss of MnSOD changes mitochondrial morphology, we performed transmission electron microscopy. While the control cells displayed the intercellular networks, microvilli-like protrusions, and lipid droplets typical for hepatocytes, these features were lost in the MnSOD-kd cells. In addition, MnSOD deficiency altered mitochondrial structure and number; the mitochondria were smaller in size and contained fewer cristae, although MnSOD-kd cells appeared to contain a higher number of mitochondria compared to the control cells (Fig. 2A).

We next investigated whether these alterations in mitochondrial structure affect mitochondrial function and analyzed the mitochondrial integrity and membrane potential by labeling active mitochondria with the fluorescent dye tetramethylrhodamine ethyl ester (TMRE). In addition, we examined alterations in cellular respiration by high-resolution respirometry. Fluorescence microscopy of TMRE-labeled cells revealed that depletion of MnSOD increased fragmentation of the mitochondrial tubes, as indicated by shortened tube structures (Fig. 2B). In addition, MnSOD-deficient cells showed about $20 \%$ reduction in the mitochondrial membrane potential compared to the control cells (Fig. 2C).
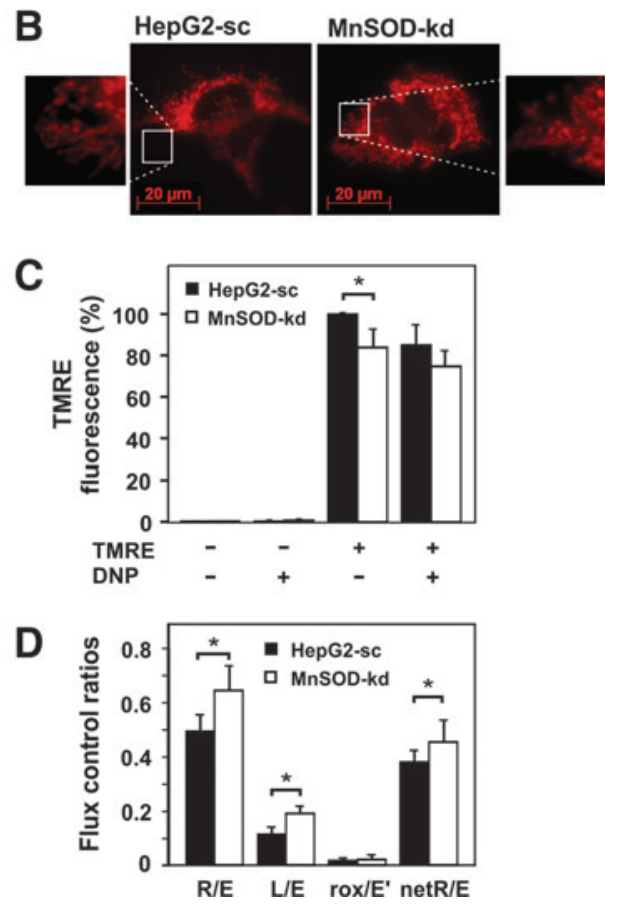

FIG. 2. MnSOD knockdown alters mitochondrial function. (A) Transmission electron microscopy images of HepG2-sc and MnSOD-kd cells at $1200 \times$ and $4800 \times$ magnification. (B) Comparison of intracellular mitochondrial networks in HepG2sc and MnSOD-kd cells visualized by TMRE (200 nM) staining and fluorescence microscopy. (C) Mitochondrial membrane potential $\left(\Delta \Psi_{\mathrm{m}}\right)$ was assessed by TMRE fluorescence using DNP as an uncoupler. Results are shown as percentage normalized to the HepG2-sc control and presented as mean $\pm \mathrm{SD}$; *Significant difference sc versus kd, $p<0.05$. (D) Oxygen consumption of HepG2-sc and MnSOD-kd cells was measured by high-resolution respirometry. Measured were routine (R) respiration, proton leak (L) respiration after oligomycin-initiated inhibition of ATP synthase (5 m $M$ oligomycin), ETC capacity (E) at FCCP-uncoupled respiration (5-7 $\mathrm{m} M$ FCCP), and nonmitochondrial respiration (rox) after inhibition of respiratory chain complexes I and III by rotenone $(1 \mathrm{mM})$ and antimycin A $(5 \mathrm{~m} M)$. Data were normalized to cell number, and the relative changes are presented. Abbreviations: $\mathrm{R} / \mathrm{E}=$ ratio of routine and noncoupled respiration, $\mathrm{L} / \mathrm{E}=\mathrm{ratio}$ of oligomycin-inhibited and noncoupled respiration, rox $/ \mathrm{E}^{\prime}=$ rate of oxidative phosphorylation-independent oxygen consumption (*Significant difference $p<0.05$ ). DNP, 2,4-dinitrophenol; ETC, electron transport chain; FCCP, carbonyl cyanide-ptrifluoromethoxyphenylhydrazone; TMRE, tetramethylrhodamine, ethyl ester. To see this illustration in color, the reader is referred to the web version of this article at www.liebertpub.com/ars 
Using high-resolution respirometry, we found that the noncoupled respiratory capacity of the electron transport system (ETS) was decreased and the proton leak after inhibition of ATP synthase with oligomycin was elevated due to MnSOD deficiency; however, the oxygen consumption during routine respiration was not affected by the loss of MnSOD. These changes in cellular respiration became very clear when comparing the flux control ratios of HepG2-sc and MnSOD-kd cells (Fig. 2D).

While control HepG2-sc cells utilized only about 50\% of the ETS's total respiratory capacity, MnSOD-depleted cells required about $65 \%$ for routine respiration. In addition, proton leakage after inhibition of ATP synthase with oligomycin indicated an increased potential of superoxide production (19\%) for MnSOD-kd cells compared to the $12 \%$ of total respiratory capacity observed for HepG2-sc cells. Interestingly, after excluding the superoxide producing respiration, about $45 \%$ of the total ETS capacity was needed for ATP production in MnSOD-kd cells, whereas only $38 \%$ was used in control cells (Fig. 2D). Together, these results indicate a mitochondrial dysfunction, where the MnSOD-kd cells leak protons and operate significantly closer to the total respiratory capacity.
In addition to the changed mitochondrial morphology and function, we also detected changes in cell morphology upon staining of cells with crystal violet. While HepG2-sc cells were spherical in shape, their MnSOD-kd derivatives showed a fibroblast-like morphology with branches and an elongated shape. Furthermore, 4',6-diamidino-2-phenylindole (DAPI) staining revealed an increased degree of DNA condensation in the nuclei of MnSOD-kd cells compared to the scrambled control cells (HepG2-sc) (Fig. 3A).

Since increased ROS may affect proliferation and cell survival, we next determined whether kd of MnSOD alters proliferation. Therefore, bromodeoxyuridine (BrdU) incorporation and MTT assays were performed along with counting of cells; they show that loss of MnSOD caused an increase in proliferation by about $50 \%$ (Fig. 3B). Apoptotic as well as necrotic cell deaths, as assessed by flow cytometry using a combination of the DNA-binding dye propidium iodide (PI) and the phospholipid-binding protein annexin $\mathrm{V}$, were not affected in MnSOD-kd cells (Fig. 3C, D). Together, these results indicate that lack of MnSOD promotes proliferation but not survival of hepatoma cells.
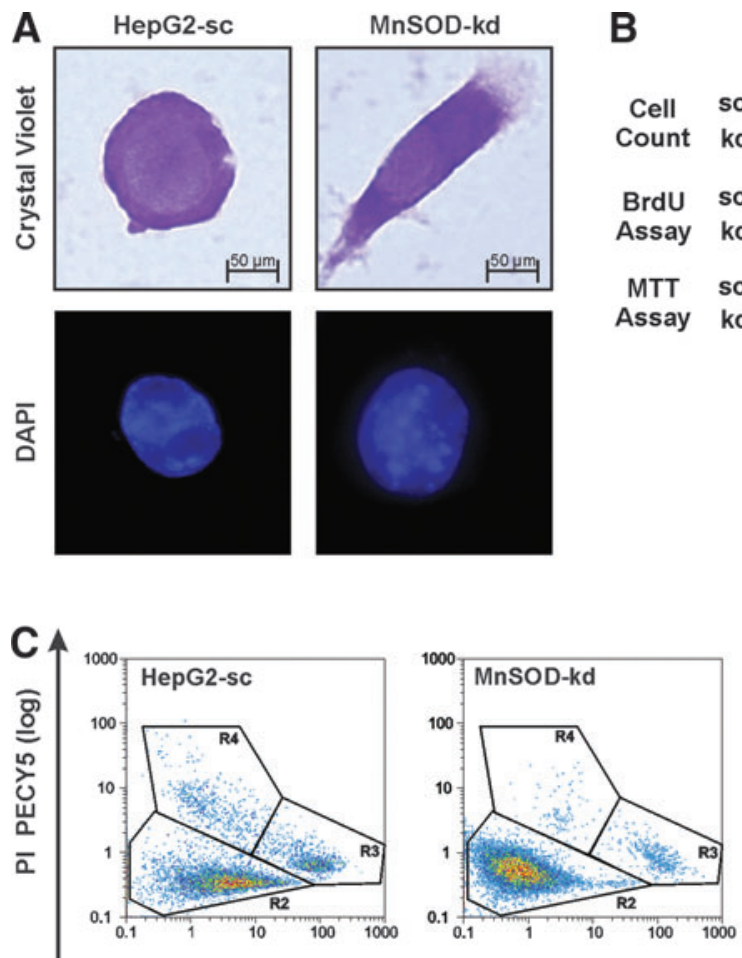

Annexin V5 FITC $(\log )$
B
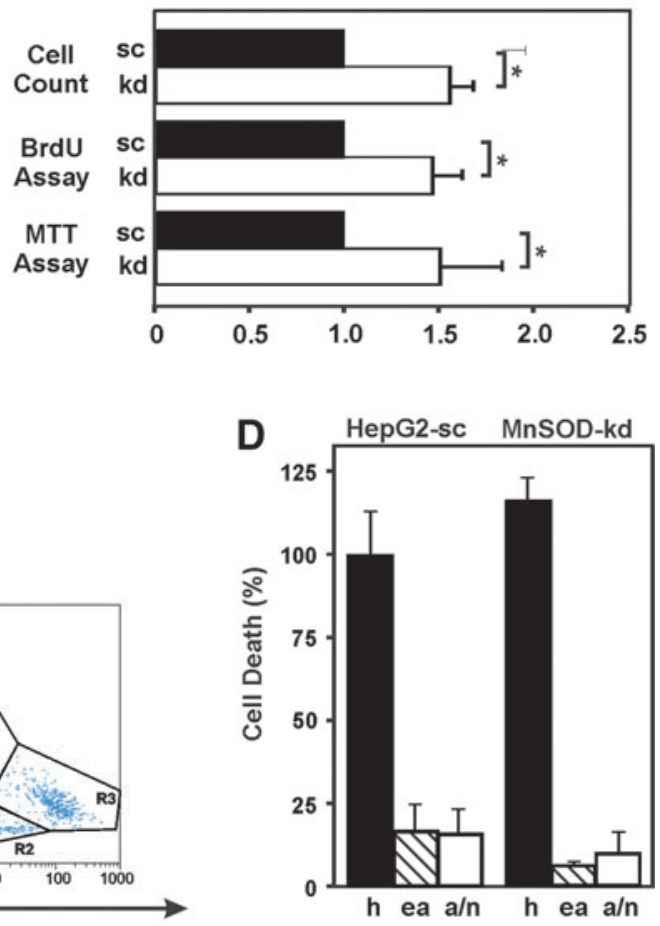

FIG. 3. Loss of MnSOD alters cell morphology and increases proliferation in HepG2 cells. (A) Representative images of HepG2-sc (sc) and MnSOD-kd (kd) cells stained with crystal violet and DAPI. Images were taken using a $60 \times / 1.00$ oil immersion objective in bright-field to visualize crystal violet staining and fluorescence at an appropriate filter set for DAPI. (B) The effect of MnSOD deficiency on the proliferative ability was measured by counting of cells, BrdU assay, and MTT assay. Data are presented as fold induction (mean \pm SD) normalized to HepG2-sc cells $(* p<0.05)$. (C) FACS analysis of apoptotic and necrotic cells after double staining with Annexin-V-FLOUS (AV) and PI at a sampling rate of $1 \mathrm{ml} / \mathrm{min}$ and wavelengths of $\lambda_{\mathrm{ex}}=488 \mathrm{~nm}, \lambda_{\mathrm{em}}=518 \mathrm{~nm}$ for AV and $\lambda_{\mathrm{ex}}=488 \mathrm{~nm}, \lambda_{\mathrm{em}}=617 \mathrm{~nm}$ for PI. Representative plot displaying AV versus PI shows three clearly separated populations of cells: R2=live (AV neg, PI neg), R3=early apoptotic (AV pos, PI neg), and R4 = late apoptotic/necrotic (AV pos, PI pos). (D) Alive (h), early apoptotic (ea), and late apoptotic/necrotic (a/n) cells analyzed by FACS. Data are mean \pm SD of the fold induction normalized to HepG2-sc cells. BrdU, bromodeoxyuridine; DAPI, 4',6-diamidino-2-phenylindole; PI, propidium iodide. To see this illustration in color, the reader is referred to the web version of this article at www.liebertpub.com/ars 


\section{MnSOD deficiency enhances malignant transformation of hepatoma cells}

Malignant cell transformation is characterized by the ability of cells to overcome contact inhibition and to grow in a semisolid environment. Indeed, soft agar assays revealed that loss of MnSOD led to growth and formation of a few large colonies ( $>100 \mu \mathrm{m}$ in diameter), which displayed about fivefold increase in colony volume, whereas HepG2-sc cells formed many small colonies $(<50 \mu \mathrm{m}$ in diameter $)$ and stopped growing soon after plating (Fig. 4A, B). In addition, after 6 days in a monolayer colony formation assay, MnSODdeficient cells covered a 40-fold larger area with loose widespread colonies compared to HepG2-sc cells that grew under the same conditions as dense overlaying colonies (Fig. 4A, B).

Next, migration and invasion of both the HepG2-sc and MnSOD-kd cells through a semipermeable membrane were studied in a transwell assay in response to serum starvation. Cell migration increased by about ninefold due to loss of MnSOD (Fig. 4C). Since tumor invasiveness is highly dependent on cell adhesion, the strength of cell attachment to the matrix of a culture plate was quantified in an adhesion assay. Properly attached cells were rotated for $2 \mathrm{~h}$ on an orbital shaker, while a control plate was kept motionless. MnSOD deficiency decreased cell adhesion significantly; about $60 \%$ detachment was observed for MnSOD-kd cells, whereas only $25 \%$ of HepG2-sc cells detached in response to motion (Fig. 4C, D). Together, these data underline that lack of MnSOD plays a role in malignant cell transformation.

\section{Lack of MnSOD in hepatocytes contributes to liver failure and precancerosis in mice}

To further investigate the role of MnSOD in liver tumorigenesis on an in vivo level, we created a hepatocyte-specific MnSOD-knockout (KO) mouse model. Although these mice appeared phenotypically normal at birth, they had a significantly decreased liver to body weight ratio (wild type [WT]: $1.90 \pm 0.26 \mathrm{~g}, \mathrm{KO}: 0.99 \pm 0.10 \mathrm{~g}$ ). The absence of MnSOD was confirmed on the level of protein expression. MnSOD protein was absent in the livers of these animals, whereas the levels in the brain and kidney were unchanged (Fig. 5A).

In line with the in vitro data, the loss of MnSOD in liver should cause an increase in ROS levels resulting in enhanced formation of 8-isoprostanes due to free radical-
A
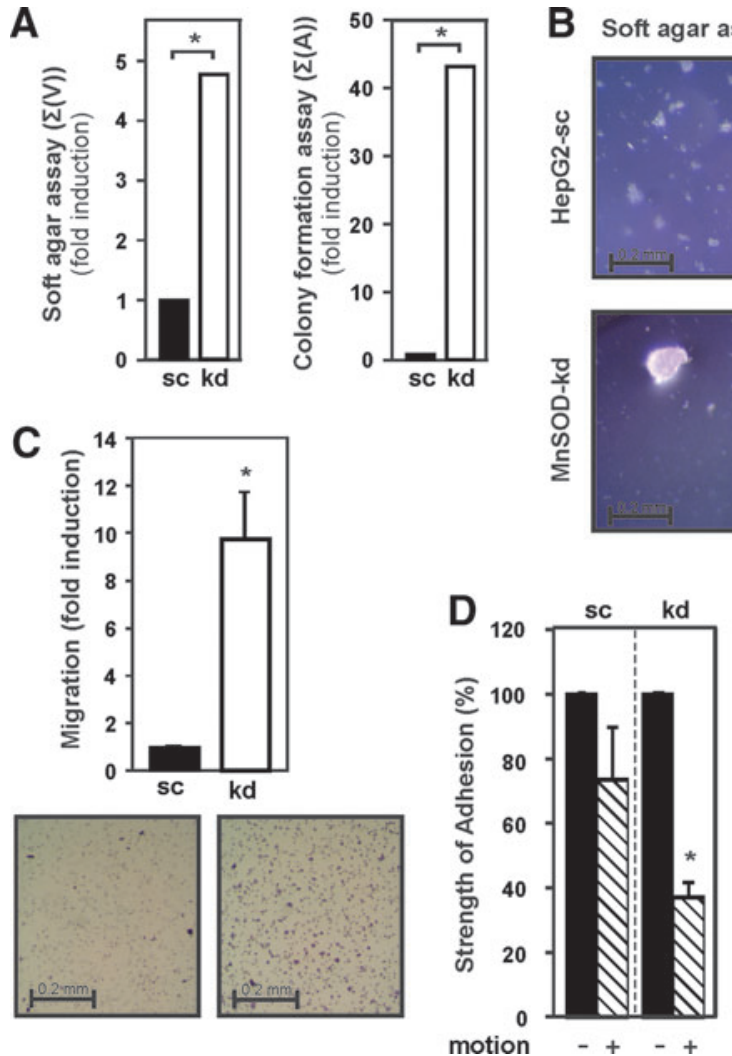

$E$
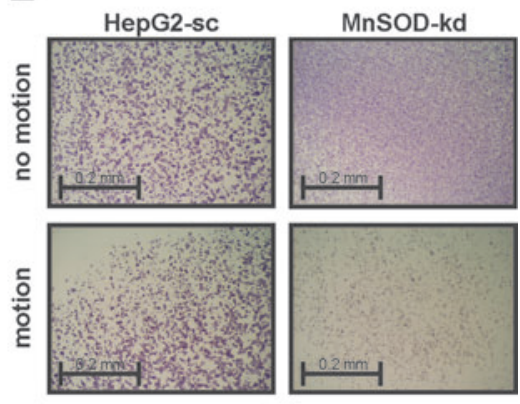

FIG. 4. MnSOD depletion affects anchorage-independent and anchorage-dependent cell growth. (A) Anchorageindependent and anchorage-dependent growth of HepG2-sc and MnSOD-kd cells was assessed by colony formation and soft agar assay, respectively. Data are presented as sum of colony volume $[\Sigma(\mathrm{V})]$ and sum of area $[\Sigma(\mathrm{A})]$, respectively. (B) Representative images from soft agar and colony formation assay are shown. (C) Migration was determined by a transwell assay ( $8 \mu \mathrm{m}$ pore size) under serum starvation. Data are mean \pm SD of the fold induction normalized to HepG2-sc cells. Representative images and quantification of migrated cells are shown. (D) Cell adhesion was assessed by rotating cells at $250 \mathrm{rpm}$ on an orbital shaker for $2 \mathrm{~h}$ at $37^{\circ} \mathrm{C}$, while keeping a control plate motionless. The number of adherent cells in the motionless control plates was set to $100 \%$; data are mean \pm SD ( $*$ Significant difference, $p<0.05)$. (E) Representative images of crystal violet stained cells still attached to the plate are shown. To see this illustration in color, the reader is referred to the web version of this article at www.liebertpub.com/ars 
A
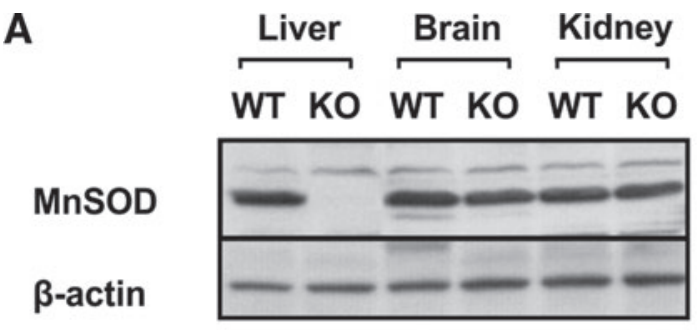

B

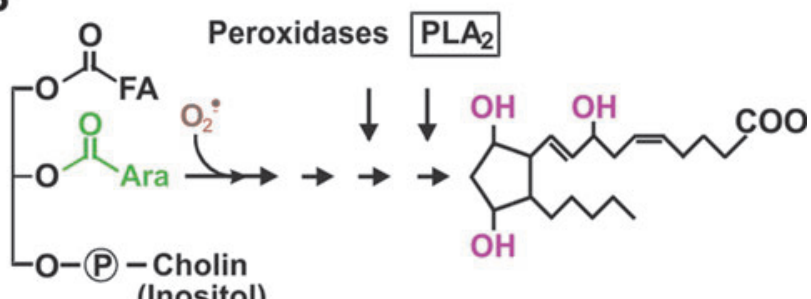

(Inositol)

Phospholipid
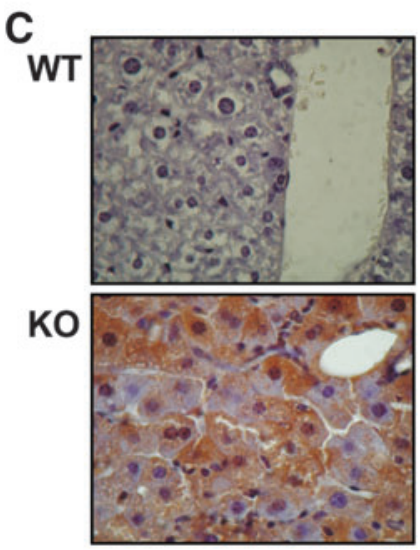

8-Isoprostane

D

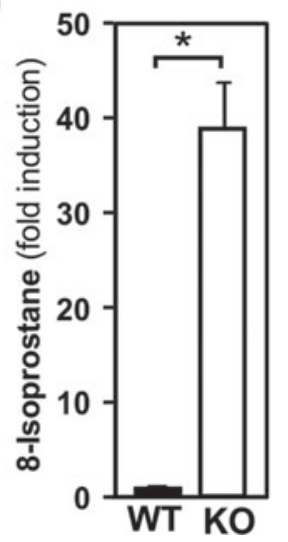

FIG. 5. Hepatocyte-specific MnSOD KO in mice induces 8-isoprostane. (A) Immunoblot analyses for MnSOD in protein lysates prepared from liver, kidney, and brain of the MnSOD ${ }^{\text {flox/flox }}$ control mice (WT) or hepatocyte-specific MnSOD-KO mice. One hundred microgram of protein was subjected to Western blot analyses with antibodies against MnSOD and $\beta$-actin. The $\beta$-actin is shown for equal loading of proteins. (B) Scheme of the superoxide-mediated peroxidation of an arachidonic acid (Ara) containing lipid. (C) Liver sections from 3-month-old, male MnSOD ${ }^{\text {floxflox }}$ control mice (WT) and MnSOD-KO mice (KO) were prepared and immunostained for 8-isoprostane. 400× magnification. (D) 8-Isoprostane staining normalized to WT and presented as mean $\pm \mathrm{SD}(n=6 /$ group; $* p<0.05)$. KO, knockout; WT, wild type. To see this illustration in color, the reader is referred to the web version of this article at www.liebertpub .com/ars

catalyzed peroxidation of arachidonic acid (Fig. 5B). To analyze this, we stained liver sections with antibodies against 8 -isoprostane. Immunostaining for 8-isoprostane was absent in the livers of control mice, whereas hepatocytes from MnSOD-KO mice displayed a very strong (40-fold increase) 8 -isoprostane signal, present in almost all hepatocytes (Fig. 5C). In addition, the enhanced generation of $\mathrm{O}_{2}{ }^{\bullet-}$ due to lack of MnSOD may, via formation of peroxynitrite, lead to protein tyrosine nitration (Fig. 6A). Indeed, liver sections

A

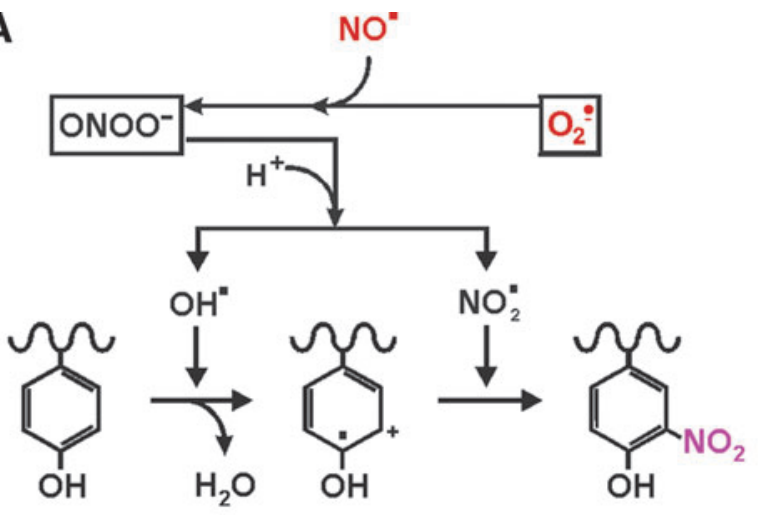

\section{Tyrosine residue \\ Tyrosylradical}

\section{3-Nitrotyrosine residue}

B
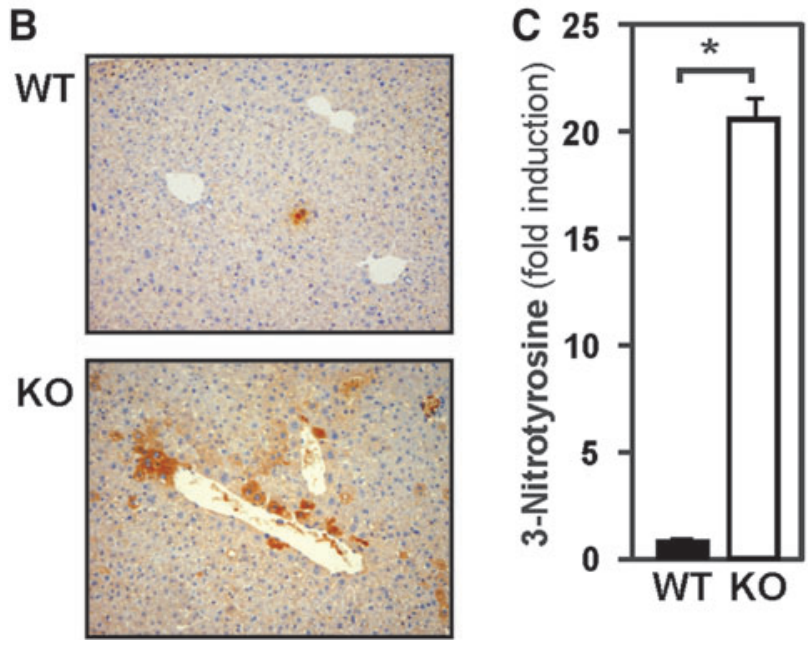

FIG. 6. Hepatocyte-specific MnSOD-KO in mice induces 3-nitrotyrosine formation. (A) Scheme of the superoxide-mediated formation of nitrotyrosine. (B) Liver sections from 3-month-old, male MnSOD ${ }^{\text {flox/flox }}$ control mice (WT) and MnSOD-KO mice (KO) were prepared and immunostained for 3-nitrotyrosine. 40× magnification. (C) 3-Nitrotyrosine formation normalized to WT and presented as mean $\pm \mathrm{SD}(n=6 /$ group; $* p<0.05)$. To see this illustration in color, the reader is referred to the web version of this article at www.liebertpub.com/ars

from MnSOD-KO mice showed about 20-fold increase in 3nitrotyrosine staining, which was almost absent in the livers of control mice (Fig. 6B, C).

To determine the pathological changes caused by loss of MnSOD on a histological basis, hematoxylin-eosin-stained liver tissue sections were examined. Sections from control mice were morphologically normal and displayed no signs of liver damage or failure (Fig. 7A, B). In contrast, livers from MnSOD-KO mice showed neoductular proliferation in the portal triads as well as periportal and intra-acinar inflammatory infiltrates of lymphocytes, leucocytes, and macrophages. Many hepatocytes exhibited intracellular lipid droplets or contained more than two nuclei (multinuclear hepatocytes). Mitotic activity was significantly increased compared with the WT livers (Fig. 7A, B). In addition, the fibrosis index as measured by the Knodell score (33) was significantly increased. 
Furthermore, evidence of liver failure due to hepatocyte injury was found on the biochemical level when the serum of MnSOD-KO and control mice was examined. The levels of albumin, a useful marker of the hepatic synthetic and secretory function, and cholinesterase, a common indicator for chronic and advanced liver disease, were markedly decreased in the MnSOD-KO mice (Fig. 7C, D). In contrast, the aminotransferases, aspartate aminotransferase and alanine aminotransferase, as well as the levels of alkaline phosphatase were increased in MnSOD-KO mice indicating hepatocellular damage. Moreover, bilirubin levels were not affected by loss of MnSOD (Fig. 7C, D).

To further examine whether the lack of MnSOD initiates neoplastic changes, we analyzed the expression of placental glutathione S-transferase (GST-P), a member of the GST

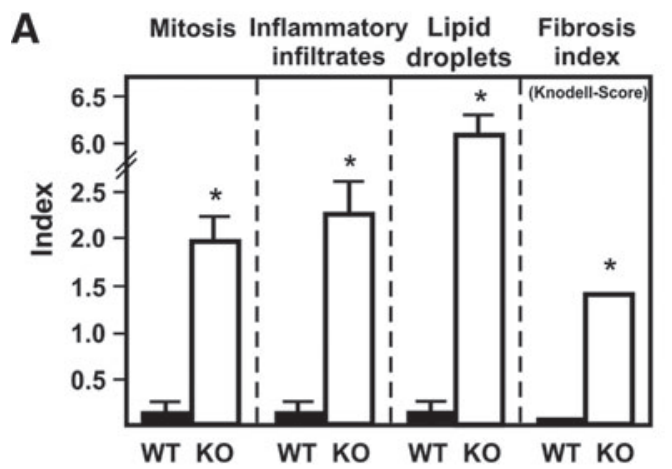

B
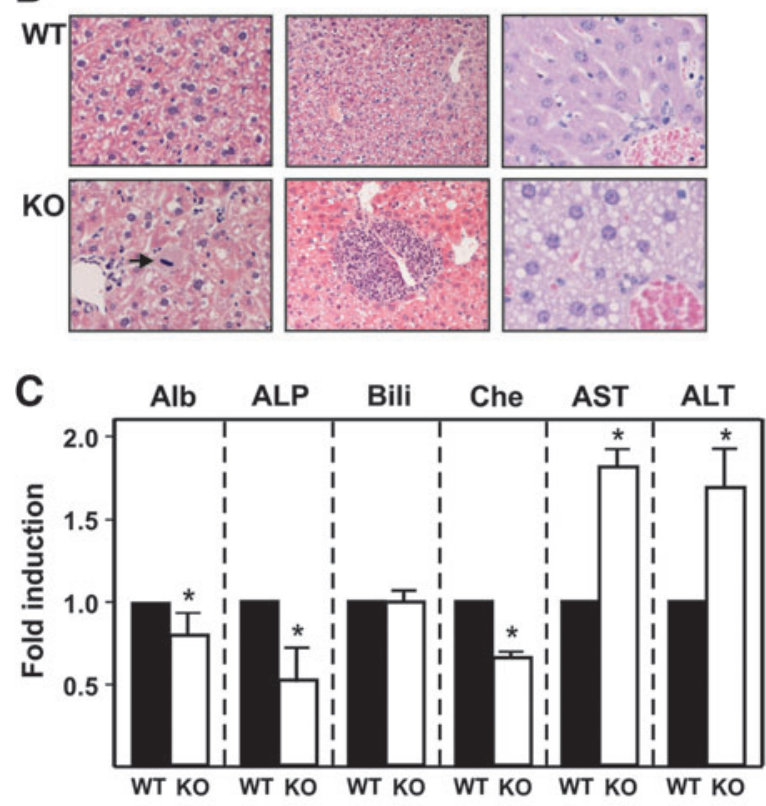

D

\begin{tabular}{lrr}
\hline Measurement & \multicolumn{1}{c}{ Control } & \multicolumn{1}{c}{ MnSOD knockout } \\
\hline Alb, g/l & $22.20 \pm 2.79$ & $18.25 \pm 4.46^{\star}$ \\
ALP, U/I & $72.60 \pm 18.24$ & $41.44 \pm 16.15^{\star}$ \\
Bilirubin, mg/dl & $0.23 \pm 0.05$ & $0.21 \pm 0.03$ \\
Che, U/I & $4.96 \pm 1.31$ & $3.85 \pm 1.34^{*}$ \\
AST, U/l & $322.48 \pm 27.45$ & $633.61 \pm 22.88^{*}$ \\
ALT, U/I & $40.43 \pm 5.05$ & $73.36 \pm 9.34^{\star}$ \\
\hline
\end{tabular}

family known as a reliable marker for hepatocarcinogenesis (52). We found that livers of control mice were completely devoid of GST-P. In contrast, MnSOD-KO mice displayed a large number of GST-P-positive cells (Fig. 8A, B), indicating structural changes within the liver acinar architecture. To further investigate this, we studied distribution of glutamine synthetase (GS), an enzyme known to be present in the most distal perivenous cells of the acinus, which thus represents a marker for acinar integrity (17). In control mice, GS was found only in the hepatocytes surrounding the central veins. In contrast, the MnSOD-KO mice displayed a scattered pattern of GS-positive cells without a clear zonal distribution, indicating that loss of MnSOD initiated structural changes within the liver acinus, which could over an extended time frame contribute to the formation of liver tumors (Fig. 8A, B). However, during the 3 -month observation period, the animals remained free of tumors (Table 1).

\section{Loss of MnSOD in hepatocytes increases diethylnitrosamine-induced tumor formation in mice}

To determine whether MnSOD deficiency affects hepatocarcinogenesis, the formation of preneoplastic lesions and adenomas in livers of hepatocyte-specific MnSOD-deficient and control mice was studied at different time points after induction of hepatocellular carcinogenesis with diethylnitrosamine (DEN). The carcinogenic effect of DEN involves bioactivation by cytochrome P450 enzymes and formation of highly carcinogenic DNA adducts through nitrosamine alkylation (58). The MnSOD-deficient DEN-injected mice displayed an increased likelihood and earlier appearance of

FIG. 7. Lack of MnSOD in hepatocytes causes liver damage. (A) Livers from 3-month-old, male MnSOD ${ }^{\text {flox/flox }}$ control mice (WT) and MnSOD-KO mice (KO) were prepared and analyzed for morphological changes. Cells showing mitotic signs, inflammatory infiltrates, and lipid droplets were counted using a $\times 400$ magnification $\left(0.15 \mathrm{~mm}^{2}\right.$ field), and the respective index (nuclei with visible chromosomes/total number of nuclei with observations at least 5000 counted nuclei) as well as the Knodell fibrosis score (33) compared to the WT animals, was determined. Data presented as mean \pm SD $(n=6 /$ group; $* p<0.05)$. (B) Representative liver sections from wild-type $\mathrm{MnSOD}^{\text {flox/flox }}$ (WT) and hepatocyte-specific MnSOD-KO mice stained with hematoxylin/eosin. The livers of hepatocyte-specific MnSOD-KO mice displayed sings of inflammation (inflammatory foci in the middle panel in KO). In addition, an enhanced number of mitotic cells (arrow in left KO) and lipid droplet containing cells (right $\mathrm{KO}$ ) were present in these animals. (C) Blood was drawn from 3-month-old, male control MnSOD ${ }^{\text {flox/flox }}$ mice (WT) and MnSOD-KO mice (KO); the individual samples of serum were analyzed for different parameters indicating liver injury. The respective levels or activities in the WT animals were set to 1 (*Significant difference $p<0.05$ ). (D) Serum parameters in the WT and KO mice, values represent mean \pm SD $(n=6 /$ group; ${ }^{*} p<0.05$, ). Alb, albumin; ALP, alkaline phosphatase; ALT, alanine aminotransferase (formerly GPT, glutamate pyruvate aminotransferase); AST, aspartate aminotransferase (formerly GOT, glutamate oxaloacetate aminotransferase); Bili, bilirubin; Che, choline esterase. To see this illustration in color, the reader is referred to the web version of this article at www.liebertpub.com/ars 
A

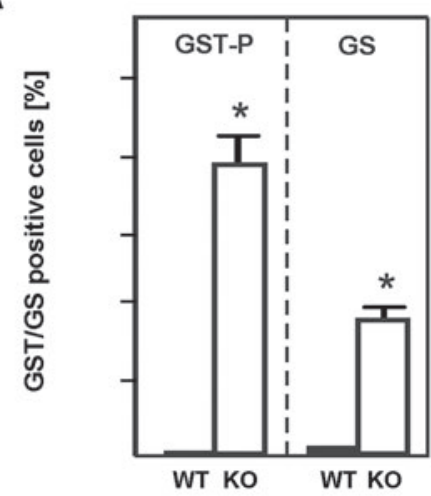

B

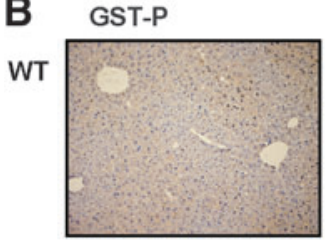

KO

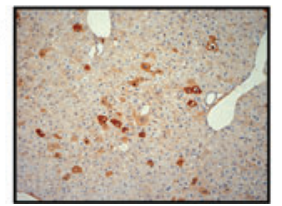

GS
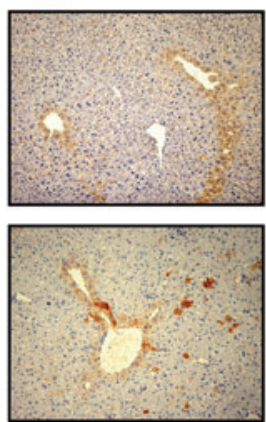

C WT

i
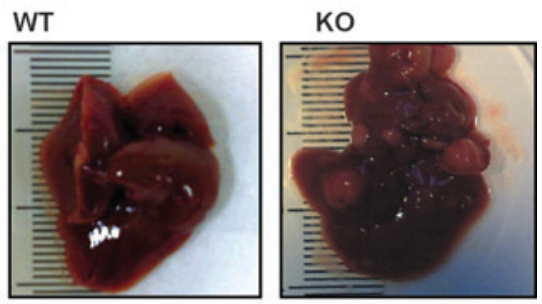

ii
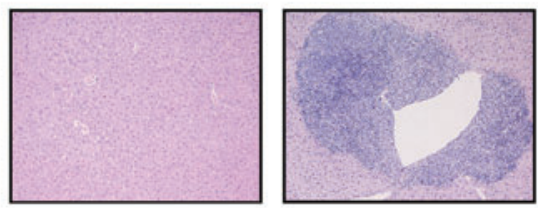

iii

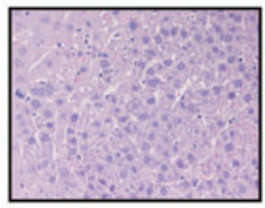

iv

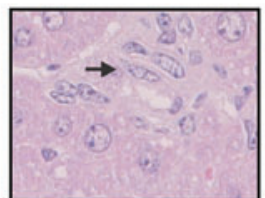

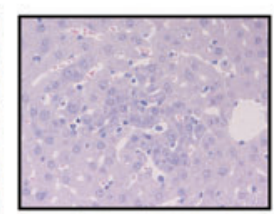

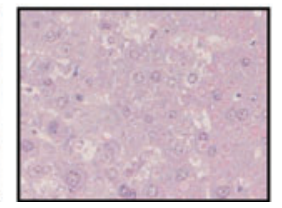

FIG. 8. Loss of MnSOD in hepatocytes promotes tumorigenesis. (A) Livers from 3-month-old, male $\mathrm{MnSOD}^{\text {flox/flox }}$ control mice (WT) and MnSOD-KO mice (KO) were prepared and immunostained for GST-P and GS, and positive cells were counted using a 40× magnification. Data represented as positive cells per 100 hepatocytic nuclei; at least 5000 nuclei have been counted $(n=6 /$ group; $* p<0.05)$. (B) Representative liver sections from wild-type MnSOD ${ }^{\text {flox/flox }}(\mathrm{WT})$ and hepatocyte-specific MnSOD-KO mice immunostained with antibodies against GST-P or GS as early tumor markers. Dark brown precipitates indicate the GST- or GS-positive cells. 40× magnification. (C) Diethylnitrosamine induced liver tumors in mice. (i) Massive DEN-induced liver tumorigenesis in hepatocyte-specific MnSOD-KO mice 12 months after DEN injection (Table 1). (ii) Large areas of perivenular chronic inflammation in the livers of KO mice compared to normal morphology of WT animals 6 months after DEN treatment; 40×. (iii) Preneoplastic lesions in WT and KO mice 9 and 6 months after DEN injection, respectively; 200×. (iv) Oval cells in WT compared to liver adenoma in KO liver tissue 12 months after DEN treatment; 400×. Hematoxylin-Eosin staining. DEN, diethylnitrosamine; GS, glutamine synthetase; GST-P, placental glutathione S-transferase. To see this illustration in color, the reader is referred to the web version of this article at www.liebertpub.com/ars

Table 1. Lack of Manganese Superoxide Dismutase in Hepatocytes Increases Adenoma Formation in Response to Diethylnitrosamine

\begin{tabular}{|c|c|c|c|c|c|}
\hline Animals & Type & 3 months & 6 months & 9 months & 12 months \\
\hline \multicolumn{6}{|c|}{ WT-MnSOD ${ }^{\text {flox/flox }}$} \\
\hline \multirow[t]{2}{*}{ DEN $(+)$} & Preneoplesia & $0(0 / 2)$ & $3 \pm 1(8 / 10)$ & $3 \pm 1(10 / 10)$ & $7 \pm 2(9 / 9)$ \\
\hline & Adenoma & $0(0 / 2)$ & $0(0 / 10)$ & $0(0 / 10)$ & $3 \pm 1(9 / 9)$ \\
\hline \multirow[t]{2}{*}{ DEN (-) } & Preneoplesia & $0(0 / 2)$ & $0(0 / 10)$ & $0(0 / 9)$ & $0(0 / 10)$ \\
\hline & Adenoma & $0(0 / 2)$ & $0(0 / 10)$ & $0(0 / 9)$ & $0(0 / 10)$ \\
\hline \multicolumn{6}{|l|}{$\mathrm{MnSOD}^{-/-}$} \\
\hline \multirow[t]{2}{*}{ DEN (+) } & Preneoplesia & $3 \pm 1(2 / 2)$ & $8 \pm 2(8 / 10)$ & $10 \pm 3 *(10 / 10)$ & $25 \pm 6 *(9 / 9)$ \\
\hline & Adenoma & $0(0 / 2)$ & $0(0 / 10)$ & $3 \pm 1 *(9 / 10)$ & $20 \pm 4 *(9 / 9)$ \\
\hline \multirow[t]{2}{*}{$\operatorname{DEN}(-)$} & Preneoplesia & $0(0 / 2)$ & $0(0 / 10)$ & $0(0 / 8)$ & $5 \pm 2 * *(9 / 9)$ \\
\hline & Adenoma & $0(0 / 2)$ & $0(0 / 10)$ & $0(0 / 8)$ & $3 \pm 1 * *(9 / 9)$ \\
\hline
\end{tabular}

Number of preneoplastic lesions and adenoma (per $\mathrm{cm}^{2}$ liver area) found in the livers of wild-type and MnSOD-deficient male mice at 3 , 6,9 , and 12 months of age. Animals are grouped into DEN treated [DEN (+)] and untreated [DEN (-)]. Mean values \pm SDs are shown; the number of lesion presenting animals versus the number of examined mice in each group is given in brackets.

*Differences between WT and KO $p<0.05$ were considered significant; ** $p<0.01$.

DEN, diethylnitrosamine; KO, knockout; MnSOD, manganese superoxide dismutase; SD, standard deviation; WT, wild type. 
hepatic preneoplastic lesions and adenomas (Table 1), pointing toward a role for MnSOD as a tumor suppressor.

Signs of preneoplastic lesions in MnSOD-KO mice were apparent already 3 months after injection of DEN, whereas in control animals, the first preneoplastic lesions appeared after 6 months. Hepatocellular adenomas appeared first in MnSOD-KO mice 9 months after DEN treatment. Twelve months after DEN injection, the livers of WT mice also displayed adenomas; however, they were 10 times more frequent in MnSOD-deficient animals. In this study, three out

A
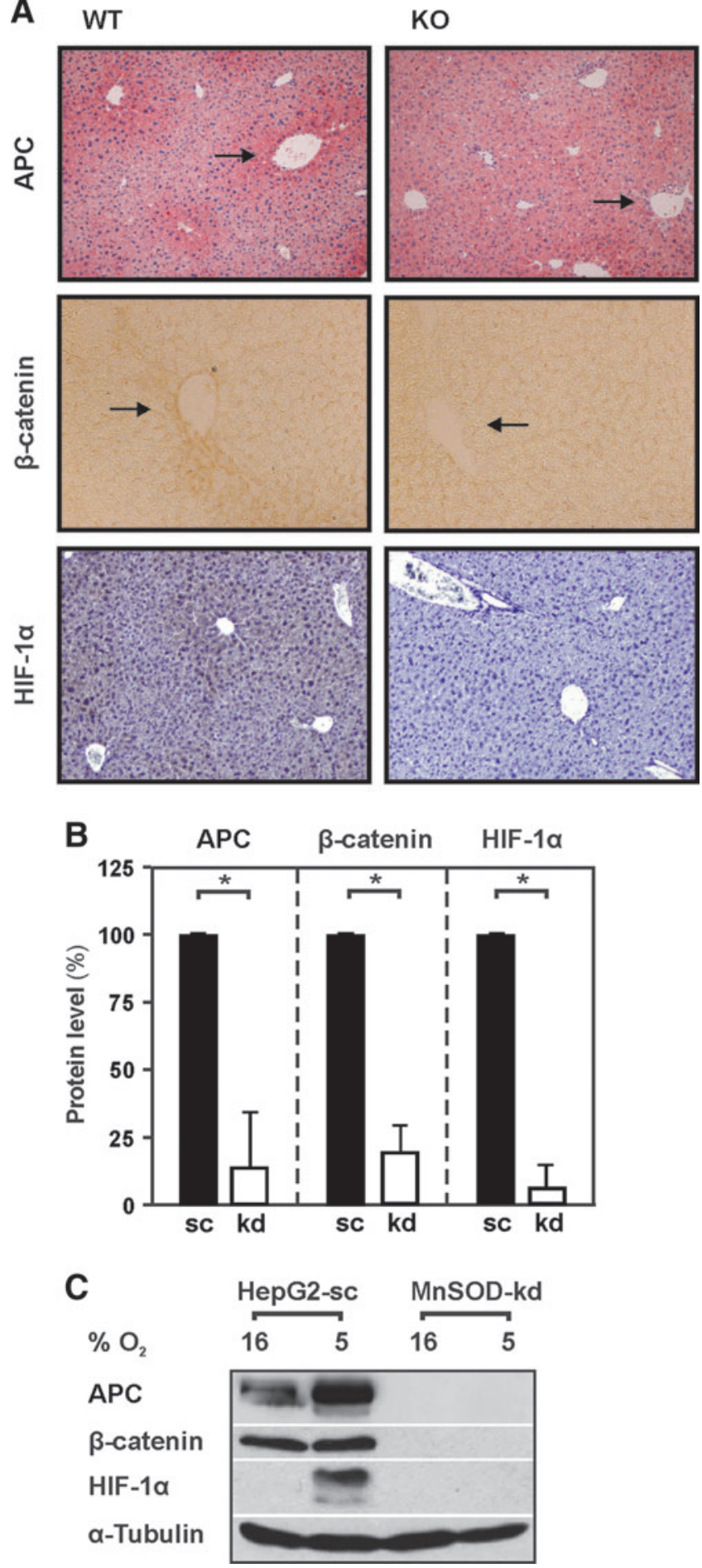

of nine DEN-treated KO mice showed liver carcinogenesis in its terminal stage, with five or more tumors of $2-5 \mathrm{~mm}$ diameter (Fig. 8C[i]). In addition, a few preneoplastic lesions and adenomas were found even in the livers of untreated MnSOD-KO mice, but not in the untreated wild-type animals, further emphasizing the role of MnSOD as a tumor suppressor.

In line, histological analyses of the hematoxylin-eosinstained liver tissues revealed large areas of perivenular inflammatory infiltrates in DEN-injected MnSOD-KO mice after 6 months (Fig. 8C[ii]). At 12 months, all of the DENtreated $\mathrm{KO}$ mice displayed an advanced stage of liver adenoma. In contrast, the livers of DEN-treated wild-type animals were almost free of tumors, but contained large numbers of oval cells, which are involved in liver regeneration after injury (Fig. 8C[iv]). Together, these data show that lack of MnSOD in hepatocytes contributes to tumor formation in the liver.

\section{Loss of MnSOD in vitro and in vivo leads \\ to inactivation of Wnt signaling and \\ to interruption of the hypoxic response}

It is well known that the $\mathrm{Wnt} / \beta$-catenin pathway is one of the most important pathways associated with carcinogenesis and malignancy (51). Moreover, loss of hepatic zonation and pericentral tissue rearrangement has recently been associated with improper Wnt signaling $(4,56)$. In light of this, we determined whether MnSOD deficiency would affect expression and distribution of $\mathrm{Wnt} / \beta$-catenin pathway components using antibodies against $\beta$-catenin and the adenoma polyposis coli (APC) protein. In line with previous findings (5), we found that APC was highly expressed in hepatocytes surrounding the central veins of wild-type mice, whereas this perivenous zonation was almost absent in MnSOD-KO animals (Fig. 9A, B).

In line, APC protein levels of MnSOD-kd cells were significantly decreased compared to HepG2-sc cells (Fig. 9C). Since APC is responsible for directing the phosphorylation and ubiquitination of $\beta$-catenin (67), the reduction in APC due to loss of MnSOD would be expected to stabilize $\beta$ catenin. In contrast, the levels of $\beta$-catenin were also found to

FIG. 9. Lack of MnSOD decreases APC, $\beta$-catenin, and HIF-1 $\alpha$ levels in vivo in mice and in vitro in HepG2 cells. (A) Representative liver sections from 3-month-old, male wild-type $\mathrm{MnSOD}^{\text {flox/flox }}$ (WT) and hepatocyte-specific MnSOD-KO mice immunostained for APC, $\beta$-catenin, and HIF- $1 \alpha$. Dark areas indicate high APC, $\beta$-catenin, and HIF$1 \alpha$ expression. (B) Quantification of immunostained tissue sections of 3-month-old animals ( $n=4$ /group; * $p<0.05$ ). (C) HepG2 cells stably transfected with a scrambled (sc) shRNA or shRNA against MnSOD (kd) were exposed to normoxia $16 \% \mathrm{O}_{2}$ or hypoxia $5 \% \mathrm{O}_{2}$ for $4 \mathrm{~h}$. Thereafter, protein lysates were prepared and analyzed by Western blotting with antibodies against APC, $\beta$-catenin, HIF- $1 \alpha$, and $\alpha$-tubulin, respectively. $\alpha$-Tubulin is shown for equal loading of proteins. Arrows indicate areas of changed expression. APC, adenoma polyposis coli; HIF- $1 \alpha$, hypoxiainducible transcription factor. To see this illustration in color, the reader is referred to the web version of this article at www.liebertpub.com/ars 

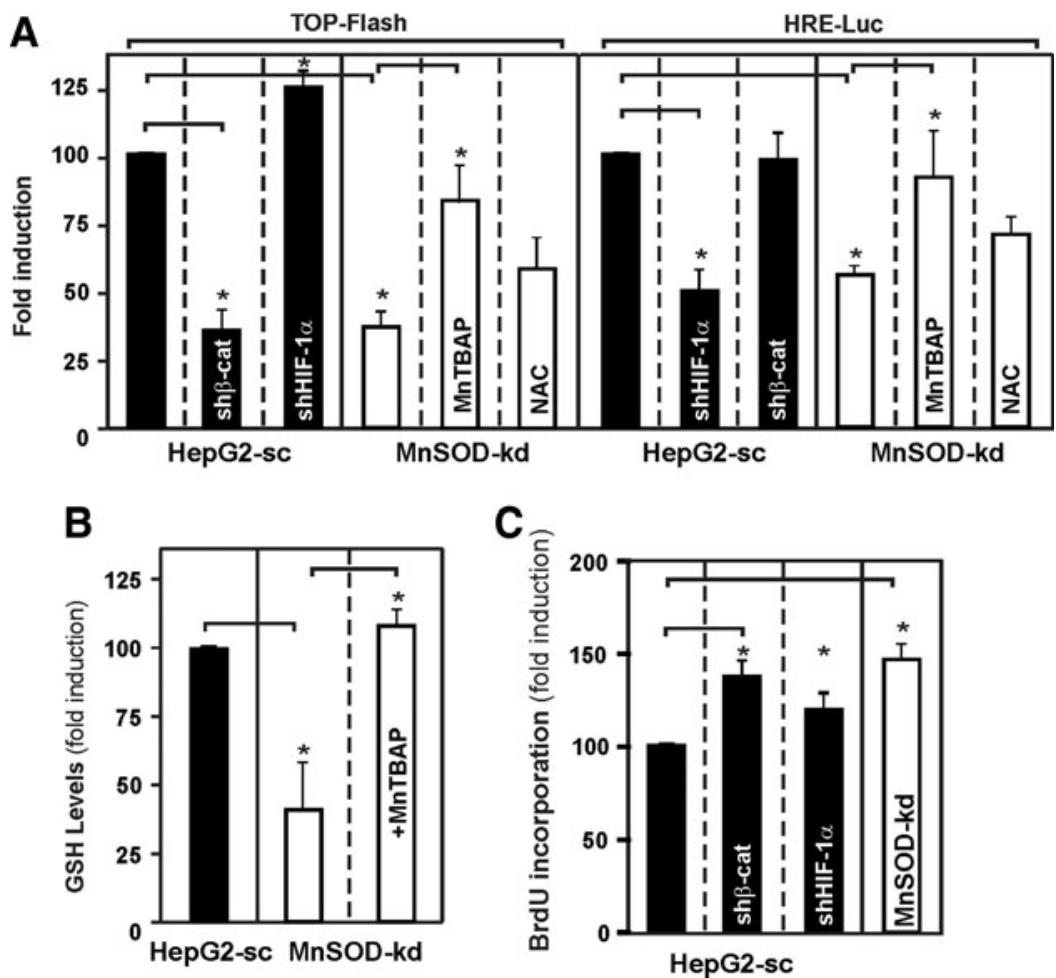

FIG. 10. MnTBAP rescues $\beta$-catenin and HIF-1 $\alpha$ activity in MnSOD lacking cells, whereas knockdown of $\beta$-catenin and HIF-1 $\alpha$ mimics lack of MnSOD in HepG2-sc cells. (A) HepG2-sc or MnSOD-kd cells were transiently transfected with either TopFlash or HRE-Luc gene constructs and were cotransfected with shRNAs against $\beta$-catenin and HIF- $1 \alpha$, or treated with MnTBAP $(100 \mu M)$ or NAC $(1 \mathrm{mM})$ for $24 \mathrm{~h}$. Luc activity levels were normalized to Renilla luciferase levels. The percentage of Luc activity was determined relatively to corresponding controls that were set equal to $100 \%$. Data are mean \pm SD (*Significant difference, $p<0.05$ ). (B) MnTBAP rescues the GSH levels in MnSOD-kd cells. HepG2-sc and MnSOD-kd cells were treated with MnTBAP $(100 \mu M)$ for $24 \mathrm{~h}$, and GSH levels were measured. Data are mean \pm SD (*Significant difference, $p<0.05$ ). (C) Knockdown of $\beta$-catenin and HIF-1 $\alpha$ mimics the proliferative phenotype of MnSOD lacking cells. HepG2-sc cells were transfected with shRNAs against HIF- $1 \alpha$ or $\beta$-catenin, controls were cotransfected with an empty vector, and BrdU assays were performed. Data are presented as fold induction (mean \pm SD) normalized to HepG2sc cells, where the BrdU level was set to $100 \%$ (*Significant difference, $p<0.05$ ). NAC, $N$-acetylcysteine; MnTBAP, $\mathrm{Mn}$ (III) tetrakis (4-benzoic acid) porphyrin chloride.

be reduced when MnSOD was knocked out in mice or knocked down in HepG2 cells (Fig. 9A-C).

Another important aspect during carcinogenesis is hypoxia signaling, where the HIF- $1 \alpha$ plays a critical role (63). Since HIF levels can be influenced by ROS (21), we were interested to see whether lack of MnSOD may have an effect on HIF-1 $\alpha$. To do this, we first analyzed HIF- $1 \alpha$ levels in the liver tissue of the wild-type and MnSOD-KO animals. We found that low levels of HIF- $1 \alpha$ could be detected around the low oxygen containing central veins of WT animals. In contrast, HIF- $1 \alpha$ was absent in the livers of MnSOD-deficient mice (Fig. 9A). Next, we exposed MnSOD-kd cells and HepG2-sc cells to normoxic and hypoxic conditions. We found that hypoxia mediated a strong upregulation of HIF- $1 \alpha$ in the control cells, whereas hypoxia failed to induce HIF- $1 \alpha$ levels in MnSOD-kd cells.

To further proof the interrelation between lack of MnSOD and the $\beta$-catenin and HIF- $1 \alpha$ pathway, we transfected HepG2-sc and MnSOD-kd cells with a $\beta$-catenin responsive TopFlash luciferase (Luc) reporter construct as well as a HIFresponsive HRE-Luc construct in combination with shRNAs against $\beta$-catenin and HIF- $1 \alpha$, respectively. We found that, in line with the Western blot analyses, MnSOD-kd cells dis- played reduced TopFlash and HRE-Luc activity similar to the ones of HepG2-sc cells cotransfected with the corresponding shRNA (Fig. 10A). In addition, we tried to rescue the reduced TopFlash and HRE-Luc activity levels by treating the transfected MnSOD-kd cells with the cell permeable MnSOD mimic $\mathrm{Mn}(\mathrm{III})$ tetrakis (4-benzoic acid) porphyrin chloride (MnTBAP). Both TopFlash and HRE-Luc expressions were induced upon treatment of MnSOD-kd cells with MnTBAP. This seemed to be a specific superoxide-driven event since treatment of cells with $\mathrm{N}$-acetylcysteine (NAC) did not induce TopFlash and HRE-Luc activities (Fig. 10A), but treatment with MnTBAP was able to restore the GSH content of MnSOD-kd cells to the level of the control (Fig. 10B).

In addition, we found that kd of HIF- $1 \alpha$ in HepG2-sc cells induced TopFlash activity, whereas $\mathrm{kd}$ of $\beta$-catenin did not affect HRE-Luc activity pointing to an interdependency of both pathways.

To estimate whether the downregulation of the $\mathrm{Wnt} / \beta$ catenin or the HIF- $1 \alpha$ signaling pathways may be involved in the transformation of HepG2-sc cells toward a malignant phenotype, HepG2-sc cells were transfected with shRNAs against $\beta$-catenin and HIF- $1 \alpha$ and proliferation was measured 
by BrdU incorporation. Indeed, $\mathrm{kd}$ of $\beta$-catenin induced proliferation by about $20 \%$, and $\mathrm{kd}$ of HIF- $1 \alpha$ promoted proliferation of HepG2-sc cells by about $15 \%$.

Together, these data suggest that lack of MnSOD can have a promoting effect on hepatocarcinogenesis via affecting $\beta$-catenin and $\mathrm{HIF}-1 \alpha$ signaling.

\section{Discussion}

The present study showed that MnSOD deficiency promotes carcinogenesis in vitro in human hepatoma cells and in vivo in liver of mice. On the cellular level, loss of MnSOD caused an increased proliferation, reduced apoptosis, decreased contact inhibition and cell adhesion, as well as enhanced migration. This was in line with the in vivo findings showing that hepatocyte-specific loss of MnSOD in mice causes liver failure, 8-isoprostane and 3-nitrotyrosine formation, as well as initiation of malignant transformation and tumor formation. In addition, MnSOD deficiency strongly promotes tumor formation in a model of chemically induced carcinogenesis. The mechanistic analyses of the in vivo and in vitro models indicate a loss of APC and $\beta$-catenin in the MnSOD-deficient cells and livers of MnSOD-deficient mice, indicating that MnSOD is a critical component necessary to sustain proper $\mathrm{Wnt} / \beta$-catenin signaling.

\section{Loss of MnSOD contributes to carcinogenesis}

First evidence that MnSOD deficiency contributes to carcinogenesis and malignancy came from numerous reports showing a relative reduction of MnSOD in many solid tumors $(54,66)$. In addition, two MnSOD variants (23), showing either reduced mitochondrial translocation or enzyme activity $(2,55)$, were associated with a higher incidence of cancer $(44,62)$, which points to the role of MnSOD as a tumor suppressor, and of oxidative stress as a promoter of liver tumors.

Supporting the concept that loss of MnSOD leads to a transformed cell type is the observed change in morphology in MnSOD-kd HepG2 hepatoma cells toward a more fibroblast-like shape. Although the branched and elongated shape of MnSOD-deficient cells would lead to the assumption that they adhere stronger to the extracellular matrix, the data showed the opposite. Loss of MnSOD decreased adhesion and increased migration of cells. The potential of MnSOD to affect migration appears not to be restricted to liver-derived cells. Recent reports indicated that changed MnSOD levels affect also migration of certain cancer cell lines as well as of vascular smooth muscle cells in vitro and in vivo $(9,37,61)$.

Changes toward a more malignant phenotype due to the loss of MnSOD were also observed in cell proliferation. Like in the present study, suppression of MnSOD by siRNA resulted in increased superoxide levels and stimulation of proliferation in ovarian cancer cells (24). Furthermore, overexpression of MnSOD has shown to inhibit cellular proliferation of numerous tumor cell types both in vitro and in vivo $(31,50,61)$. These findings are in line with studies demonstrating changes in MnSOD during the cell cycle. MnSOD levels were decreased during the $S$ phase (48), while increased MnSOD levels were observed in nonproliferating cells in the $G_{0}$ phase (7).
Although the ROS generated due to MnSOD deficiency do not necessarily need to be carcinogenic, they can initiate or participate in reactions that contribute to transformation of cells and to a carcinogenic process. The concept that loss of MnSOD leads to a transformed cell type is supported by our findings from hepatocyte-specific MnSOD-KO mice displaying an enhanced number of GST-P- and GS-positive cells. Enhanced levels of GST isoenzymes as precancerosis markers were also found in hepatic preneoplastic nodules (7), suggesting that hepatocyte-specific loss of MnSOD induces development of hepatocellular carcinomas. The appearance of GST-positive cells is in line with the role of ROS as tumor promoters since $\mathrm{H}_{2} \mathrm{O}_{2}$ was shown to induce GST in different cell types $(1,53)$. Moreover, GSTs also detoxify some of the carbonyl-, peroxide-, and epoxide-containing metabolites produced within xenobiotic metabolism, where ROS are produced as byproducts. Interestingly, similar neoplastic changes were also observed in livers of $\mathrm{Cu} / \mathrm{Zn}-\mathrm{SOD}^{-1-}$ mice (14). Like our hepatocyte-specific MnSOD-KO mice, the nonconditional $\mathrm{Cu} / \mathrm{Zn}-\mathrm{SOD}^{-/-}$mice were born without a significant phenotype, but exhibited an increased incidence of nodular hyperplasia or hepatocellular carcinoma as well as neurodegeneration, and reduced fertility later in life (14). In addition, other antioxidant enzymes may contribute to the development of human hepatocellular carcinoma; for example, Gpx activity was found to be reduced in hepatocellular carcinoma patients compared to histologically normal livers (6).

Carcinogenesis is also accompanied by structural reorganization or remodeling of tissue. In the liver, various enzymes are distributed in a zonated manner, that is, they can be found in the periportal, intermediate, or perivenous zone $(26,27)$. In the healthy liver, GS is found only in distal perivenous hepatocytes $(16,17)$. However, our MnSOD-KO mice clearly showed GS-positive cells in other areas. GSproducing cells may possess a growth advantage (49), as well as a higher metastatic potential (19), which coincides with the phenotypic changes due to MnSOD deficiency in HepG 2 cells. Since glutamine is an energy source of tumors, GS positivity indicates that these cells produce their own glutamine, independent from that supplied by the blood. Together, the lost GS zonation and the presence of GSTpositive cells (Fig. 8A, B) appear to represent early hepatocellular carcinogenesis.

MnSOD deficiency in the livers of male humans and rodents has been associated with nonalcoholic fatty liver disease (NAFLD) (35). While NAFLD does not necessarily lead to liver cancer, it is a known cause of chronic liver disease, which possesses a risk for progression to cirrhosis and hepatic carcinogenesis (43). Although not enough epidemiological data are available to show whether loss of MnSOD is cause or consequence of NAFLD, our findings provide a link indicating that loss of MnSOD may be carcinogenic. In line with this, the additional increase in oxidative stress due to chemical induction of hepatocarciogenisis with DEN resulted in an early-onset and increased incidence of hepatic preneoplastic lesions and liver adenomas in hepatocyte-specific MnSOD-deficient mice. This together with the presence of enhanced oxidative stress seen as 8-isoprostane and 3nitrotyrosine immunohistochemical staining (Figs. 6 and 7) indeed supports the role of oxidative stress as a tumor promoter in the liver. 
The involvement of Wnt and hypoxia signaling in hepatocarcinogenesis

The Wnt/ $\beta$-catenin pathway, as one of the most important pathways associated with cancer, has been specifically implicated with liver tumors. Mutations leading to accumulation of $\beta$-catenin were found in $17 \%$ of hepatocellular carcinomas (64). Therefore, we determined whether MnSOD deficiency affects expression and distribution of the Wnt pathway components $\beta$-catenin and APC. Surprisingly, both were decreased in MnSOD-deficient HepG2 hepatoma cells as well as in MnSOD absent mouse livers, indicating a dysregulation of $\beta$-catenin on expression rather than on stability. In line with our study, hepatocyte-specific $\beta$-catenin KO mice showed increased susceptibility to DEN-induced carcinogenesis (69). Paradoxically, hepatocyte-specific disruption of the APC gene in mice also resulted in activation of Wnt/ $\beta$-catenin signaling and hepatocarcinogenesis (69), indicating that any imbalance in Wnt signaling may promote tumor development in the liver.

Since hypoxia plays an important role in tumor progression and the ability of cells to survive under low oxygen conditions is a key feature of malignant tumors, it was one of the aspects of this work to investigate HIF- $1 \alpha$ protein levels. Indeed, induction of HIF- $1 \alpha$ was disrupted both in vitro and in vivo due to the loss of MnSOD. These findings are partially in line with previous observations from MnSOD overexpressing human breast carcinoma MCF-7 cells, where hypoxia-dependent induction of HIF- $1 \alpha$ was lost when MnSOD activity was moderately increased but restored when under highly increased MnSOD activity. Furthermore, overexpression of $\mathrm{H}_{2} \mathrm{O}_{2}$ metabolizing enzymes in these high MnSOD-expressing cells prevented HIF- $1 \alpha$ induction under hypoxia. Thus, it was believed that the increase in HIF- $1 \alpha$ is mediated by mitochondrial hydrogen peroxide (63).

Overall, these observations as well as the data presented here may follow the same regulatory mechanism of HIF- $1 \alpha$ degradation. VHL-dependent degradation of HIF- $1 \alpha$ is known to require the presence of $\mathrm{Fe}^{2+}$ as a cofactor for the prolyl hydroxylases (PHDs), which hydroxylate HIF-1 $\alpha$ at conserved proline residues, mediating proteasomal degradation (63). While $\mathrm{O}_{2}^{--}$in general causes reduction of iron, $\mathrm{H}_{2} \mathrm{O}_{2}$ oxidizes it to $\mathrm{Fe}^{3+}$. Thus, it is tempting to speculate that $\mathrm{kd}$ of MnSOD and accumulation of $\mathrm{O}_{2}{ }^{--}$would increase PHD activity and therefore HIF- $1 \alpha$ degradation, whereas expression of MnSOD and accumulation of $\mathrm{H}_{2} \mathrm{O}_{2}$ would decrease PHD activity and prevent HIF $\alpha$ degradation.

Although our data do not unravel all mechanistic aspects of the carcinogenic process in response to MnSOD deficiency, they indicate that the interplay between HIF- $1 \alpha$ and $\beta$-catenin contributes to this effect. The $\beta$-catenin/HIF- $1 \alpha$ interplay appears to be complex, partially conflicting, and is far from being completely understood. Initial reports indicated that $\beta$ catenin is able to interact with HIF- $1 \alpha$ to mediate hypoxic adaptation (28), which would imply that HIF signaling may negatively affect $\beta$-catenin signaling under emerging hypoxic conditions to allow immediate adaptation of a tumor. Indeed, several reports indicate that hypoxia and HIF- $1 \alpha$ can block and even downregulate $\beta$-catenin protein levels $(11,39$, $59,60)$. These findings would be in line with our data indicating that $\mathrm{kd}$ of $\mathrm{HIF}-1 \alpha$ increases $\beta$-catenin-dependent TopFlash activity.
However, other reports showed that hif- $1 \alpha$ deletion can also impair Wnt-dependent processes, including neuronal stem cell proliferation, differentiation, and neuronal maturation (41). As a consequence, loss of the $\beta$-cateninmediated differentiating effect promotes a dedifferentiated state of cells, which in terms of cancer represents a more malignant status than a well-differentiated one. This is in line with our findings showing loss of $\beta$-catenin due to lack of MnSOD as well as with a study from 97 hepatocellular carcinoma patients where $76 \%$ of the patients displayed a reduced expression of $\beta$-catenin correlating with poor survival (68).

Although hypoxia usually correlates with a malignant behavior of cancer cells, it has been recently shown that HIF$1 \alpha$ is also responsible for the induction of cell cycle inhibitors such as p21 and p27 (20). Thus, lack of HIF- $1 \alpha$ and $\beta$-catenin in MnSOD cells would promote progression into the $S$ phase and at the same time inhibit cell differentiation with the consequence to have a procarcinogenic effect.

Although not enough epidemiological data are available to show whether loss of MnSOD is a general carcinogenic phenomenon, our study shows that hepatocyte-specific loss of MnSOD contributes to the induction of hepatotoxicity and liver cancer, which appear to involve the $\mathrm{Wnt} / \beta$-catenin pathway and HIF- $1 \alpha$ signaling, as well as their interplay, as crucial elements.

\section{Materials and Methods}

All biochemicals and enzymes used were of analytical grade and were obtained from commercial suppliers.

\section{Cells}

Stable transfectants of human HepG2 hepatoma cells were established using a MnSOD miRNA-expressing vector and a respective scrambled control vector. Both cell lines, a mixed population of MnSOD-kd and HepG2-sc, were cultured under normoxia $\left(16 \% \mathrm{O}_{2}, 5 \% \mathrm{CO}_{2}\right.$, and $\left.79 \% \mathrm{~N}_{2}[\mathrm{v} / \mathrm{v}]\right)$ or when indicated under hypoxia $\left(5 \% \mathrm{O}_{2}, 5 \% \mathrm{CO}_{2}\right.$, and $\left.90 \% \mathrm{~N}_{2}[\mathrm{v} / \mathrm{v}]\right)$ at $37^{\circ} \mathrm{C}$ in minimal essential medium (MEM) supplemented with $10 \%$ fetal bovine serum (FBS), $1 \%$ nonessential amino acids, and $0.5 \%$ ciprofloxacin hydrochloride.

\section{ROS detection}

The total ROS content of cells was assessed using $2^{\prime}, 7^{\prime}$ dichlorodihydrofluorescein diacetate $\left(\mathrm{H}_{2} \mathrm{DCF}-\mathrm{DA}\right)$, whereas DHE was used to measure superoxide levels. Cells $\left(10^{4}\right.$ cells/ well) cultured on 96-well plates were washed with $1 \times$ phosphate-buffered saline (PBS) and incubated with $10 \mu M$ $\mathrm{H}_{2}$ DCF-DA (Molecular Probes) or $10 \mu M$ DHE (Sigma) in $1 \times \mathrm{PBS}$ for $15 \mathrm{~min}$ at $37^{\circ} \mathrm{C}$. After replacement of the reactive agents with $1 \times$ PBS, DCF formation was recorded at $\lambda_{\mathrm{ex}} / \lambda_{\mathrm{em}}: 495 / 529 \mathrm{~nm}$ and DHE fluorescence at $\lambda_{\mathrm{ex}} / \lambda_{\mathrm{em}}: 530 /$ $610 \mathrm{~nm}$ using a Tecan infinite M1000Pro microplate reader (Tecan). Values were corrected for $\mathrm{H}_{2}$ DCF-DA and DHE auto-oxidation in $1 \times \mathrm{PBS}$. For live cell imaging of DHE, fluorescence cells were plated onto $35 \mu \mathrm{m} \mu$-dishes (Ibidi) and treated with $20 \mu M$ DHE (Sigma) for $15 \mathrm{~min}$, and after washing with PBS, images of cells were taken using a confocal microscope LSM700 (Zeiss) at the appropriate filter set for DHE. 


\section{GSH assay}

GSH levels were measured using $o$-phthaldialdehyde (OPT) as a fluorescent agent (22). HepG2-sc and MnSOD-kd cells were washed with $1 \times \mathrm{PBS}$, resuspended at $10^{6}$ cells $/ \mathrm{ml}$ in a lysis buffer (5\% trichloroacetic acid, $1 \mathrm{~m} M$ ethylenediaminetetraacetic acid [EDTA], $0.1 M \mathrm{HCl}, 1: 1: 1$, v/v/v), and incubated on a roller for $20 \mathrm{~min}$ at $4{ }^{\circ} \mathrm{C}$. Following lysis, insoluble material was spun down at $5600 \mathrm{~g}$ for $20 \mathrm{~min}$ at $4^{\circ} \mathrm{C}$. After mixing 18 parts of $0.1 M \mathrm{Na}_{2} \mathrm{HPO}_{4} / 5 \mathrm{~m} M$ EDTA ( $\mathrm{pH}$ $8.0)$, one part of OPT $(0.1 \mathrm{mg} / \mathrm{ml}$ in methanol), and one part of sample supernatant, fluorescence was measured at $\lambda_{\mathrm{ex}} / \lambda_{\mathrm{em}}$ : $350 / 420 \mathrm{~nm}$ using a Tecan infinite M1000Pro microplate reader (Tecan).

\section{Transmission electron microscopy}

Cells were fixed in $1 \%$ glutaraldehyde and $4 \%$ formaldehyde mixture in $0.1 \mathrm{M}$ phosphate buffer for $10 \mathrm{~min}$. Cells were detached, and fixation was continued for $1 \mathrm{~h}$. After fixation, cells were centrifuged, immersed in $2 \%$ agarose in distilled water, postfixed in $1 \%$ osmium tetroxide, dehydrated in acetone, and embedded in Epon LX 112 (Ladd Research Industries). Thin sections were cut with a Leica Ultracut UCT ultramicrotome, stained in uranyl acetate and lead citrate, and examined in a Tecnai G2 Spirit transmission electron microscope (FEI Europe). Images were captured by using a Quemesa CCD camera (Olympus Soft Imaging Solutions GMBH).

\section{TMRE mitochondrial staining}

TMRE is a cell membrane permeant, positively-charged fluorescent dye that accumulates in the active mitochondria. Treatment with carbonyl cyanide- $p$-trifluoromethoxyphenylhydrazone (FCCP) or 2,4-dinitrophenol (DNP) uncouples the ETS from the oxidative phosphorylation, thereby decreasing the proton gradient of mitochondria. For live cell imaging of TMRE, fluorescence cells were plated onto 35$\mu \mathrm{m} \mu$-dishes (ibidi) and treated with $200 \mathrm{n} M$ TMRE (Sigma) for $30 \mathrm{~min}$. Cells treated with $20 \mu M$ FCCP (Sigma) $10 \mathrm{~min}$ before TMRE staining were included as a depolarization control. After washing with PBS, images of cells were taken using an Observer Z1 live cell analyzing microscope (Zeiss) at the appropriate filter set for TMRE $\left(\lambda_{\mathrm{ex}} / \lambda_{\mathrm{em}}: 549 \mathrm{~nm} /\right.$ $575 \mathrm{~nm})$. The mitochondrial membrane potential was determined after treating cells $\left(10^{4}\right.$ cells/well) on 96 -well plates with $1 \mu M$ TMRE for $30 \mathrm{~min}$. Treatment with $2 \mathrm{~m} M$ DNP (Sigma) for $10 \mathrm{~min}$ before TMRE staining served as a control for depolarized mitochondria. Controls for fluorescent TMRE autofluorescence were included. After washing with $0.2 \%$ bovine serum albumin (BSA) in PBS, the fluorescence was measured using a Tecan infinite M1000Pro microplate reader $\left(\lambda_{\mathrm{ex}} / \lambda_{\mathrm{em}}: 549 \mathrm{~nm} / 575 \mathrm{~nm}\right)$.

\section{Oxygen consumption}

Oxygen consumption measurements were performed using an Oxygraph-2k (Oroboros). Before each measurement, a background calibration of MEM supplemented with HEPES $(10 \mathrm{~m} M)$ was conducted under contact to the gas phase (air). Cells $\left(\sim 10^{6}\right.$ cells $\left./ \mathrm{ml}\right)$ in MEM-HEPES were measured in parallel at $37^{\circ} \mathrm{C}$ and under stirring at $750 \mathrm{rpm}$ and oxygen exclusion. The oxygen flux was allowed to stabilize till the aerobic metabolic activity under routine conditions (ROU-
TINE respiration) was reached. The proton leakage caused by ATP synthase inhibition (LEAK respiration) was determined by $1-2 \mu 1$ injections of oligomycin $(5 \mathrm{mM})$. Then, the maximal capacity of the ETS (respiration) was measured by sequential injections of FCCP $(1 \mathrm{~m} M)$ until no further increase in $\mathrm{O}_{2}$ flow could be achieved. Finally, single injections of rotenone $(1 \mathrm{mM})$ and antimycin $\mathrm{A}(5 \mathrm{~m} M)$ were implemented to completely inhibit complex I and III for the determination of oxidative phosphorylation-independent oxygen consumption (rox). The rox flux was subtracted from the other respiratory states for data analysis.

\section{$D A P I$ and crystal violet staining}

Cells were grown on glass coverslips within six-well plates at low confluence. After washing, cells were fixed with $4 \%$ paraformaldehyde and stained with $0.0075 \%$ crystal violet. Excess stain was removed, and glass coverslips were placed with a drop of Mounting Medium containing DAPI (Duolink II) onto a microscope slide. In addition, single stain controls were prepared. Images were taken at the Olympus BX51 microscope using an NPL (normal field of view plan) $60 \times /$ 1.00 oil immersion objective.

\section{Cell proliferation}

Determination of cell number. Cells $\left(4 \times 10^{5}\right)$ were seeded in 100-mm culture dishes, and cell number was determined by counting with a hemocytometer after 5 days.

BrdU assay. Incorporation of BrdU into newly synthesized DNA was detected by immunolabeling according to the manufacturer's (Merck Millipore) instructions using $2 \times 10^{4}$ cells per well in a 96-well culture plate.

MTT assay. Cell viability was assessed by measuring conversion of the yellow (3-[4,5-dimethylthiazol-2-yl]-2,5 diphenyl tetrazolium bromide) into dark blue water-insoluble formazan crystals (46). The extent of MTT reduction was quantified by spectrophotometry at $570 \mathrm{~nm}$.

\section{Flow cytometry analysis}

Fluorescence double staining with Annexin-V-FLOUS and PI was performed according to the instructions provided with the Annexin-V-FLUOS Staining Kit (Roche). Approximately, $10^{6}$ cells were washed with $1 \times$ PBS before being resuspended in $100 \mu \mathrm{l}$ Annexin-V-FLUOS labeling solution and incubated for $20 \mathrm{~min}$ at room temperature. Two sets of controls were included: single stain controls for electronic compensation of the plot and necrosis-positive controls using $0.01 \%$ Nonidet P40. Data were collected using a CyFlow Space flow cytometer (Partec) at a sampling rate of $1 \mathrm{ml} / \mathrm{min}$. Excitation wavelength was $488 \mathrm{~nm}$, and emission wavelength was $518 \mathrm{~nm}$ for Annexin-V-FLUOS and $617 \mathrm{~nm}$ for PI.

\section{Colony formation}

Anchorage-independent growth was analyzed in a threelayer soft agar assay, containing a basal agar layer followed by a cell and a top agar layer. The agar layers were prepared by mixing prewarmed $\left(37^{\circ} \mathrm{C}\right) 2 \times$ MEM (containing $20 \%$ FBS, $2 \%$ nonessential amino acids, and $1 \%$ ciprofloxacin) with an equal volume of agarose (DNA grade). For the basal 
and top layer, $1.2 \%$ agar was used, while only $0.8 \%$ agar was used for the cell containing layer with 2000 cells/well. A fifty microliter suspension was used for each layer per well of a 96 -well plate. The plates were incubated at $37^{\circ} \mathrm{C}$ for 14 days before the colonies were visualized with resazurin $(50 \mu \mathrm{l} /$ well, $0.2 \mu \mathrm{g} / \mathrm{ml}$ ) and colonies were counted and measured for quantification. Anchorage-dependent growth was assessed in a monolayer colony formation assay by seeding cells at different densities (500-3000 cells/well in steps of 500) in sixwell plates and growing them for 6 days. Afterward, cells were fixed and stained with crystal violet and analyzed as described above.

\section{Migration assay}

Migration of cells was assessed in vitro in a transwell assay, where the cells migrate through an $8.0 \mu \mathrm{m}$ polycarbonate membrane of 24-well transwell chambers (Becton Dickinson Labware) in the course of serum starvation. Cells were seeded into the top chamber at a density of $10^{5}$ cells/well in $100 \mu \mathrm{l}$ of serum-free MEM; the bottom chamber was filled with $600 \mu \mathrm{l}$ MEM containing $10 \%$ FBS. After $16 \mathrm{~h}$ in a humidified incubator, cells were fixed and stained with crystal violet as described above. The nonmigrated cells were removed from the upper surface of the Transwell membrane with a cotton swab.

\section{Cell adhesion}

Cells $\left(4 \times 10^{5}\right)$ were seeded onto 24 -well culture plates, and after attachment, one plate was placed in an orbital shaker and rotated for $2 \mathrm{~h}$ at $250 \mathrm{rpm}$ and $37^{\circ} \mathrm{C}$, while a control plate was kept motionless. Adherent cells were stained with crystal violet as described above as well as quantified by the MTT assay described above.

\section{Western analysis}

Western blot analysis was carried out as described (30). In brief, $100 \mu \mathrm{g}$ of protein was loaded onto sodium dodecyl sulfate-polyacrylamide gels and after electrophoresis blotted onto a nitrocellulose membrane. The primary antibodies against MnSOD (SOD2) (\#574596; Calbiochem), SOD1 (\#574597; Calbiochem), Nrf-2 (\#ab62352; abcam), HO-1 (\#SPA-895; assay designs), Catalase (\#8841; Cell Signaling), GPx-1 (\#3206; Cell Signaling), Prdx1 (\#8499; Cell Signaling), Prdx3 (\#sc-59661; Santa Cruz), Trn2 (\#14907; Cell Signaling), HIF-1 $\alpha$ (\#610959; D Biosciences), APC (\#sc896; Santa Cruz), Lamin A/C (\#sc-7292; Santa Cruz), and $\beta$-catenin (\#sc-7963; Santa Cruz) were used in a 1:1000 dilution. The secondary antibody was either an anti-sheep, anti-mouse, or anti-rabbit immunoglobulin $\mathrm{G}$ horseradish peroxidase (1:5000; Santa Cruz Biotechnology). The enhanced chemiluminescence system (Amersham) was used for detection.

\section{Plasmid constructs, cell transfection, and luciferase assay}

The $\beta$-catenin responsive Topflash Firefly luciferase (Luc) construct (45), the HIF-responsive HRE-Luc (29) construct, and the expression vectors for shHIF-1 $\alpha(15)$, as well as for $\operatorname{sh} \beta$-cat (34), have been previously described. Cells $\left(4 \times 10^{5}\right)$ per $60-\mathrm{mm}$ dish were transfected essentially as described
(30). In brief, $2 \mu \mathrm{g}$ of the appropriate $\beta$-catenin-responsive Topflash Firefly Luc or HIF-responsive HRE-Luc construct was cotransfected in duplicate and, to control transfection efficiency, with $0.25 \mu \mathrm{g}$ of a Renilla luciferase expression construct (pRLSV40) (Promega). After $12 \mathrm{~h}$, the medium was changed and the cells were further cultured for $24 \mathrm{~h}$, where indicated also in the presence of MnTBAP $(100 \mu M)$ or NAC $(1 \mathrm{~m} M)$. The detection of luciferase activity was performed with the Dual-Glo Luciferase Assay Kit (Promega).

\section{Animals}

The hepatocyte-specific MnSOD-KO mice $\left(\mathrm{MnSOD}^{-/}\right.$, $\mathrm{KO})$ used in this study were described (30). Control mice $\left(\mathrm{MnSOD}^{\text {flox/flox }}\right)$ are referred to as WT. Animals were housed in specific pathogen-free facilities on a 12-h light/12-h dark cycle, at a constant temperature of $22^{\circ} \mathrm{C}$, and were fed a standard diet and received water ad libitum. Hepatocellular carcinogenesis in these mice was induced by a single intraperitoneal injection of DEN ( $20 \mu \mathrm{g} / \mathrm{g}$ body weight) 2 weeks after birth. A total of 122 animals were included in this experiment-62 wild-type and $60 \mathrm{MnSOD}-\mathrm{KO}$ mice, of which 32 and 30 received DEN injections, respectively (Table 1). Three, six, nine, and twelve months following the DEN treatment, animals were euthanized by $\mathrm{CO}_{2}$ inhalation and livers were examined. All protocols for animal use and experiments were approved by the Animal Care Committee of local institutions (30).

\section{Histology and immunohistochemistry}

Mouse livers fixed in $10 \%$ neutral buffered formalin were embedded in paraffin, and $5 \mu \mathrm{m}$ sections were stained with hematoxylin and eosin according to standard techniques. Inflammatory infiltrates and cells undergoing mitosis were counted and the respective index was estimated (observations per 100 hepatocytes). For immunohistochemical staining, $5 \mu \mathrm{m}$ paraffin sections were prepared by deparaffinization and rehydration with xylenes and a graded ethanol series, respectively. Tissue sections were boiled in $0.1 \mathrm{M}$ citric acid, $\mathrm{pH}$ 6.0, endogenous peroxidase activity was quenched with $3 \% \mathrm{H}_{2} \mathrm{O}_{2}$ in methanol and nonspecific binding blocked with $5 \%$ BSA in T-PBS. The primary antibodies and the secondary peroxidase-conjugated antibodies were applied in 1\% BSA in PBS overnight at $4^{\circ} \mathrm{C}$ or $60 \mathrm{~min}$ at room temperature, respectively. Antibodies against 8-isoprostane (\#IS20; Oxford Biochemical Research), 3-nitrotyrosine (\#N0409; Sigma), APC (\#sc-896; Santa Cruz), $\beta$-catenin (\#sc-7963; Santa Cruz), HIF-1 $\alpha$ (\#NB100-449; Novus Biologicals), GS (\#ab73593; Abcam), and GST-P (\#ab170323; Abcam) were used in 1:200 dilutions. Diaminobenzidine (Pierce) 1:10 diluted in peroxidase buffer (Pierce) was used for detection, and in some cases, sections were counterstained with hematoxylin.

\section{Statistical analysis}

Densitometry data were plotted as the fold induction of relative density units, with the zero value absorbance in each figure set arbitrarily to 1 or $100 \%$. Statistical evaluation was conducted by the paired, two-tailed Student's $t$-test, and differences of $p<0.05$ were considered statistically significant. The results are presented as mean \pm standard deviation. 


\section{Acknowledgments}

This work was supported by grants from CIMO, Biocenter Oulu, and the Sigrid Juselius Foundation.

\section{Author Disclosure Statement}

No competing financial interests exist.

\section{References}

1. Aniya $\mathrm{Y}$ and Anders MW. Activation of rat liver microsomal glutathione S-transferase by reduced oxygen species. J Biol Chem 264: 1998-2002, 1989.

2. Borgstahl GEO, Parge HE, Hickey MJ, Johnson MJ, Boissinot M, Hallewell RA, Lepock JR, Cabelli DE, and Tainer JA. Human mitochondrial manganese superoxide dismutase polymorphic variant Ile58Thr reduces activity by destabilizing the tetrameric interface. Biochemistry $(N Y)$ 35: 4287-4297, 1996.

3. Bravard A, Sabatier L, Hoffschir F, Ricoul M, Luccioni C, and Dutrillaux B. SOD2: a new type of tumor-suppressor gene? Int J Cancer 51: 476-480, 1992.

4. Burke ZD, Reed KR, Phesse TJ, Sansom OJ, Clarke AR, and Tosh D. Liver zonation occurs through a $\beta$-catenindependent, c-Myc-INDEPENDENT mechanism. Gastroenterology 136: 2316-2324.e3, 2009.

5. Burke ZD and Tosh $\mathrm{D}$. The $\mathrm{Wnt} / \beta$-catenin pathway: master regulator of liver zonation? Bioessays 28: 1072-1077, 2006.

6. Casaril M, Gabrielli GB, Dusi S, Nicoli N, Bellisola G, and Corrocher R. Decreased activity of liver glutathione peroxidase in human hepatocellular carcinoma. Eur J Cancer Clin Oncol 21: 941-944, 1985.

7. Chaudhuri L, Nicholson AM, Kalen AL, and Goswami PC. Preferential selection of MnSOD transcripts in proliferating normal and cancer cells. Oncogene 31: 12071216, 2012.

8. Church SL, Grant JW, Ridnour LA, Oberley LW, Swanson PE, Meltzer PS, and Trent JM. Increased manganese superoxide dismutase expression suppresses the malignant phenotype of human melanoma cells. Proc Natl Acad Sci U S A 90: 3113-3117, 1993.

9. Connor KM, Hempel N, Nelson KK, Dabiri G, Gamarra A, Belarmino J, Van De Water L, Mian BM, and Melendez JA. Manganese superoxide dismutase enhances the invasive and migratory activity of tumor cells. Cancer Res 67: 10260-10267, 2007.

10. Cyr AR, Brown KE, McCormick ML, Coleman MC, Case AJ, Watts GS, Futscher BW, Spitz DR, and Domann FE. Maintenance of mitochondrial genomic integrity in the absence of manganese superoxide dismutase in mouse liver hepatocytes. Redox Biol 1: 172-177, 2013.

11. Dere R, Perkins AL, Bawa-Khalfe T, Jonasch D, and Walker CL. $\beta$-Catenin links von Hippel-Lindau to Aurora kinase A and loss of primary cilia in renal cell carcinoma. J Am Soc Nephrol 26: 553-564, 2015.

12. Dhar SK and St. Clair DK. Manganese superoxide dismutase regulation and cancer. Free Radic Biol Med 52: 2209-2222, 2012.

13. Dhar SK, Tangpong J, Chaiswing L, Oberley TD, and St. Clair DK. Manganese superoxide dismutase is a p53regulated gene that switches cancers between early and advanced stages. Cancer Res 71: 6684-6695, 2011.

14. Elchuri S, Oberley TD, Qi W, Eisenstein RS, Roberts LJ, Van Remmen H, Epstein CJ, and Huang T-. CuZnSOD deficiency leads to persistent and widespread oxidative damage and hepatocarcinogenesis later in life. Oncogene 24: 367-380, 2005.

15. Flügel D, Görlach A, and Kietzmann T. GSK-3 $\beta$ regulates cell growth, migration, and angiogenesis via Fbw7 and USP28-dependent degradation of HIF-1a. Blood 119: 12921301, 2012.

16. Gaasbeek Janzen JW, Gebhardt R, ten Voorde GH, Lamers WH, Charles R, and Moorman AF. Heterogeneous distribution of glutamine synthetase during rat liver development. J Histochem Cytochem 35: 49-54, 1987.

17. Gebhardt R and Mecke D. Heterogeneous distribution of glutamine synthetase among rat liver parenchymal cells in situ and in primary culture. EMBO J 2: 567-570, 1983.

18. This reference has been deleted.

19. Gebhardt R and Williams GM. Glutamine synthetase and hepatocarcinogenesis. Carcinogenesis 16: 1673-1681, 1995.

20. Goda N, Ryan HE, Khadivi B, McNulty W, Rickert RC, and Johnson RS. Hypoxia-inducible factor 1a is essential for cell cycle arrest during hypoxia. Mol Cell Biol 23: 359 369, 2003.

21. Görlach A and Kietzmann T. Superoxide and derived reactive oxygen species in the regulation of hypoxiainducible factors. Methods Enzymol 435: 421-446, 2007.

22. Hissin PJ and Hilf R. A fluorometric method for determination of oxidized and reduced glutathione in tissues. Anal Biochem 74: 214-226, 1976.

23. Ho Y and Crapo JD. Isolation and characterization of complementary DNAs encoding human manganesecontaining superoxide dismutase. FEBS Lett 229: 256260, 1988.

24. Hu Y, Rosen DG, Zhou Y, Feng L, Yang G, Liu J, and Huang P. Mitochondrial manganese-superoxide dismutase expression in ovarian cancer: role in cell proliferation and response to oxidative stress. J Biol Chem 280: 3948539492, 2005.

25. Ikegami T, Suzuki Y, Shimizu T, Isono K, Koseki H, and Shirasawa T. Model mice for tissue-specific deletion of the manganese superoxide dismutase (MnSOD) gene. Biochem Biophys Res Commun 296: 729-736, 2002.

26. Jungermann $\mathrm{K}$ and Kietzmann $\mathrm{T}$. Zonation of parenchymal and nonparenchymal metabolism in liver. Annu Rev Nutr 16: 179-203, 1996.

27. Jungermann $\mathrm{K}$ and Kietzmann T. Oxygen: modulator of metabolic zonation and disease of the liver. Hepatology 31: 255-260, 2000.

28. Kaidi A, Williams AC, and Paraskeva C. Interaction between $\beta$-catenin and HIF-1 promotes cellular adaptation to hypoxia. Nat Cell Biol 9: 210-217, 2007.

29. Kietzmann T, Cornesse Y, Brechtel K, Modaressi S, and Jungermann K. Perivenous expression of the mRNA of the three hypoxia-inducible factor a-subunits, HIF1a HIF2a and HIF3a, in rat liver. Biochem J 354: 531-537, 2001.

30. Kietzmann T, Roth U, and Jungermann K. Induction of the plasminogen activator inhibitor-1 gene expression by mild hypoxia via a hypoxia response element binding the hypoxia-inducible factor-1 in rat hepatocytes. Blood 94: 4177-4185, 1999.

31. Kim KH, Rodriguez AM, Carrico PM, and Melendez JA. Potential mechanisms for the inhibition of tumor cell growth by manganese superoxide dismutase. Antioxid Redox Signal 3: 361-373, 2001. 
32. Kinnula VL and Crapo JD. Superoxide dismutases in the lung and human lung diseases. Am J Respir Crit Care Med 167: 1600-1619, 2003.

33. Knodell RG, Ishak KG, and Black WC. Formulation and application of a numerical scoring system for assessing histological activity in asymptomatic chronic active hepatitis. Hepatology 1: 431-435, 1981.

34. Kozlova N, Jensen JK, Chi TF, Samoylenko A, and Kietzmann T. PAI-1 modulates cell migration in a LRP1dependent manner via $\beta$-catenin and ERK1/2. Thromb Haemost 113: 988-998, 2015.

35. Krautbauer S, Eisinger K, Lupke M, Wanninger J, Ruemmele P, Hader Y, Weiss TS, and Buechler C. Manganese superoxide dismutase is reduced in the liver of male but not female humans and rodents with non-alcoholic fatty liver disease. Exp Mol Pathol 95: 330-335, 2013.

36. Lenart J, Dombrowski F, Görlach A, and Kietzmann T. Deficiency of manganese superoxide dismutase in hepatocytes disrupts zonated gene expression in mouse liver. Arch Biochem Biophys 462: 238-244, 2007.

37. Li F, Wang H, Huang C, Lin J, Zhu G, Hu R, and Feng H. Hydrogen peroxide contributes to the manganese superoxide dismutase promotion of migration and invasion in glioma cells. Free Radic Res 45: 1154-1161, 2011.

38. Li J, Oberley LW, St. Clair DK, Ridnour LA, and Oberley TD. Phenotypic changes induced in human breast cancer cells by overexpression of manganese-containing superoxide dismutase. Oncogene 10: 1989-2000, 1995.

39. Lim J, Chun Y, and Park J. Hypoxia-inducible factor-1a obstructs a wnt signaling pathway by inhibiting the hARD1mediated activation of $\beta$-catenin. Cancer Res 68: 51775184, 2008.

40. Liu X, Wang A, Muzio LL, Kolokythas A, Sheng S, Rubini C, Ye H, Shi F, Yu T, Crowe DL, and Zhou X. Deregulation of manganese superoxide dismutase (SOD2) expression and lymph node metastasis in tongue squamous cell carcinoma. BMC Cancer 10: 365, 2010.

41. Mazumdar J, O’Brien WT, Johnson RS, Lamanna JC, Chavez JC, Klein PS, and Simon MC. O2 regulates stem cells through $\mathrm{Wnt} / \beta$-catenin signalling. Nat Cell Biol 12: 1007-1013, 2010.

42. Miar A, Hevia D, Muñoz-Cimadevilla H, Astudillo A, Velasco J, Sainz RM, and Mayo JC. Manganese superoxide dismutase (SOD2/MnSOD)/catalase and SOD2/GPx1 ratios as biomarkers for tumor progression and metastasis in prostate, colon, and lung cancer. Free Radic Biol Med 85: 45-55, 2015.

43. Michelotti GA, Machado MV, and Diehl AM. NAFLD, NASH and liver cancer. Nat Rev Gastroenterol Hepatol 10: 656-665, 2013.

44. Mitrunen K, Sillanpää P, Kataja V, Eskelinen M, Kosma V, Benhamou S, Uusitupa M, and Hirvonen A. Association between manganese superoxide dismutase (MnSOD) gene polymorphism and breast cancer risk. Carcinogenesis 22: 827-829, 2001.

45. Molenaar $M$, Van De Wetering $M$, Oosterwegel $M$, Peterson-Maduro J, Godsave S, Korinek V, Roose J, Destrée $\mathrm{O}$, and Clevers H. XTcf-3 transcription factor mediates $\beta$-catenin-induced axis formation in xenopus embryos. Cell 86: 391-399, 1996.

46. Mosmann T. Rapid colorimetric assay for cellular growth and survival: application to proliferation and cytotoxicity assays. J Immunol Methods 65: 55-63, 1983.
47. Oberley LW and Buettner GR. Role of superoxide dismutase in cancer: a review. Cancer Res 39: 1141-1149, 1979.

48. Oberley TD, Schultz JL, Li N, and Oberley LW. Antioxidant enzyme levels as a function of growth state in cell culture. Free Radic Biol Med 19: 53-65, 1995.

49. Osada T, Nagashima I, Tsuno NH, Kitayama J, and Nagawa $\mathrm{H}$. Prognostic significance of glutamine synthetase expression in unifocal advanced hepatocellular carcinoma. J Hepatol 33: 247-253, 2000.

50. Ough M, Lewis A, Zhang Y, Hinkhouse MM, Ritchie JM, Oberley LW, and Cullen JJ. Inhibition of cell growth by overexpression of manganese superoxide dismutase (MnSOD) in human pancreatic carcinoma. Free Radic Res 38: 1223-1233, 2004.

51. Polakis P. Wnt signaling and cancer. Genes Dev 14: 18371851, 2000.

52. Satoh K, Kitahara A, Soma Y, Inaba Y, and Hatayama I. Purification, induction, and distribution of placental glutathione transferase: a new marker enzyme for preneoplastic cells in the rat chemical hepatocarcinogenesis. Proc Natl Acad Sci U S A 82: 3964-3968, 1985.

53. Shen $H$, Tsuchida $S$, Tamai K, and Sato K. Identification of cysteine residues involved in disulfide formation in the inactivation of glutathione transferase P-form by hydrogen peroxide. Arch Biochem Biophys 300: 137-141, 1993.

54. St. Clair DK and Holland JC. Complementary DNA encoding human colon cancer manganese superoxide dismutase and the expression of its gene in human cells. Cancer Res 51: 939-943, 1991.

55. Sutton A, Khoury H, Prip-Buus C, Cepanec C, Pessayre D, and Degoul F. The Ala16Val genetic dimorphism modulates the import of human manganese superoxide dismutase into rat liver mitochondria. Pharmacogenetics 13: 145-157, 2003.

56. Torre $\mathrm{C}$, Perret $\mathrm{C}$, and Colnot $\mathrm{S}$. Transcription dynamics in a physiological process: beta-catenin signaling directs liver metabolic zonation. Int J Biochem Cell Biol 43: 271-278, 2011.

57. Van Remmen H, Hamilton ML, and Richardson A. Oxidative damage to DNA and aging. Exerc Sport Sci Rev 31: 149-153, 2003.

58. Verna L, Whysner J, and Williams GM. N-nitrosodiethylamine mechanistic data and risk assessment: bioactivation, DNA-adduct formation, mutagenicity, and tumor initiation. Pharmacol Therapeut 71: 57-81, 1996.

59. Verras M, Papandreou I, Lim AL, and Denko NC. Tumor hypoxia blocks Wnt processing and secretion through the induction of endoplasmic reticulum stress. Mol Cell Biol 28: 7212-7224, 2008.

60. Wang D, Wang Y, Kong T, Fan F, and Jiang Y. Hypoxiainduced $\beta$-catenin downregulation involves $\mathrm{p} 53$-dependent activation of Siah-1. Cancer Sci 102: 1322-1328, 2011.

61. Wang JN, Shi N, and Chen SY. Manganese superoxide dismutase inhibits neointima formation through attenuation of migration and proliferation of vascular smooth muscle cells. Free Radic Biol Med 52: 173-181, 2012.

62. Wang LI, Miller DP, Sai Y, Liu G, Su L, Wain JC, Lynch TJ, and Christiani DC. Manganese superoxide dismutase alanine-to-valine polymorphism at codon 16 and lung cancer risk. J Natl Cancer Inst 93: 1818-1821, 2001.

63. Wang M, Kirk JS, Venkataraman S, Domann FE, Zhang HJ, Schafer FQ, Flanagan SW, Weydert CJ, Spitz DR, Buettner GR, and Oberley LW. Manganese superoxide dismutase suppresses hypoxic induction of hypoxia- 
inducible factor-1a and vascular endothelial growth factor. Oncogene 24: 8154-8166, 2005.

64. Wong CM, Fan ST, and Ng IO. $\beta$-Catenin mutation and overexpression in hepatocellular carcinoma: clinicopathologic and prognostic significance. Cancer 92: 136-145, 2001.

65. Xu Y, Fang F, Dhar SK, Bosch A, St. Clair WH, Kasarskis EJ and St. Clair DK. Mutations in the SOD2 promoter reveal a molecular basis for an activating protein 2-dependent dysregulation of manganese superoxide dismutase expression in cancer cells. Mol Cancer Res 6: 1881-1893, 2008.

66. Yamanaka $\mathrm{N}$ and Deamer D. Superoxide dismutase activity in WI-38 cell cultures: effects of age, trypsinization and SV-40 transformation. Physiol Chem Phys 6: 95-106, 1974.

67. Zachariae W and Nasmyth K. Whose end is destruction: cell division and the anaphase-promoting complex. Genes Dev 13: 2039-2058, 1999.

68. Zhai B, Yan H, Liu S, Chen L, Wu M, and Wang H. Reduced expression of E-cadherin/catenin complex in hepatocellular carcinomas. World J Gastroenterol 14: 56655673, 2008.

69. Zhang $X$, Tan X, Zeng G, Misse A, Singh S, Kim Y, Klaunig JE, and Monga SPS. Conditional $\beta$-catenin loss in mice promotes chemical hepatocarcinogenesis: role of oxidative stress and platelet-derived growth factor receptor a/phosphoinositide 3-kinase signaling. Hepatology 52: 954-965, 2010.

70. Zhong W, Oberley LW, Oberley TD, and St. Clair DK. Suppression of the malignant phenotype of human glioma cells by overexpression of manganese superoxide dismutase. Oncogene 14: 481-490, 1997.

Address correspondence to: Prof. Thomas Kietzmann Faculty of Biochemistry and Molecular Medicine, and Biocenter Oulu University of Oulu Aapistie $7 B$ Oulu 90230 Finland

E-mail: tkietzm@gwdg.de

Date of first submission to ARS Central, March 4, 2015; date of acceptance, September 29, 2015.

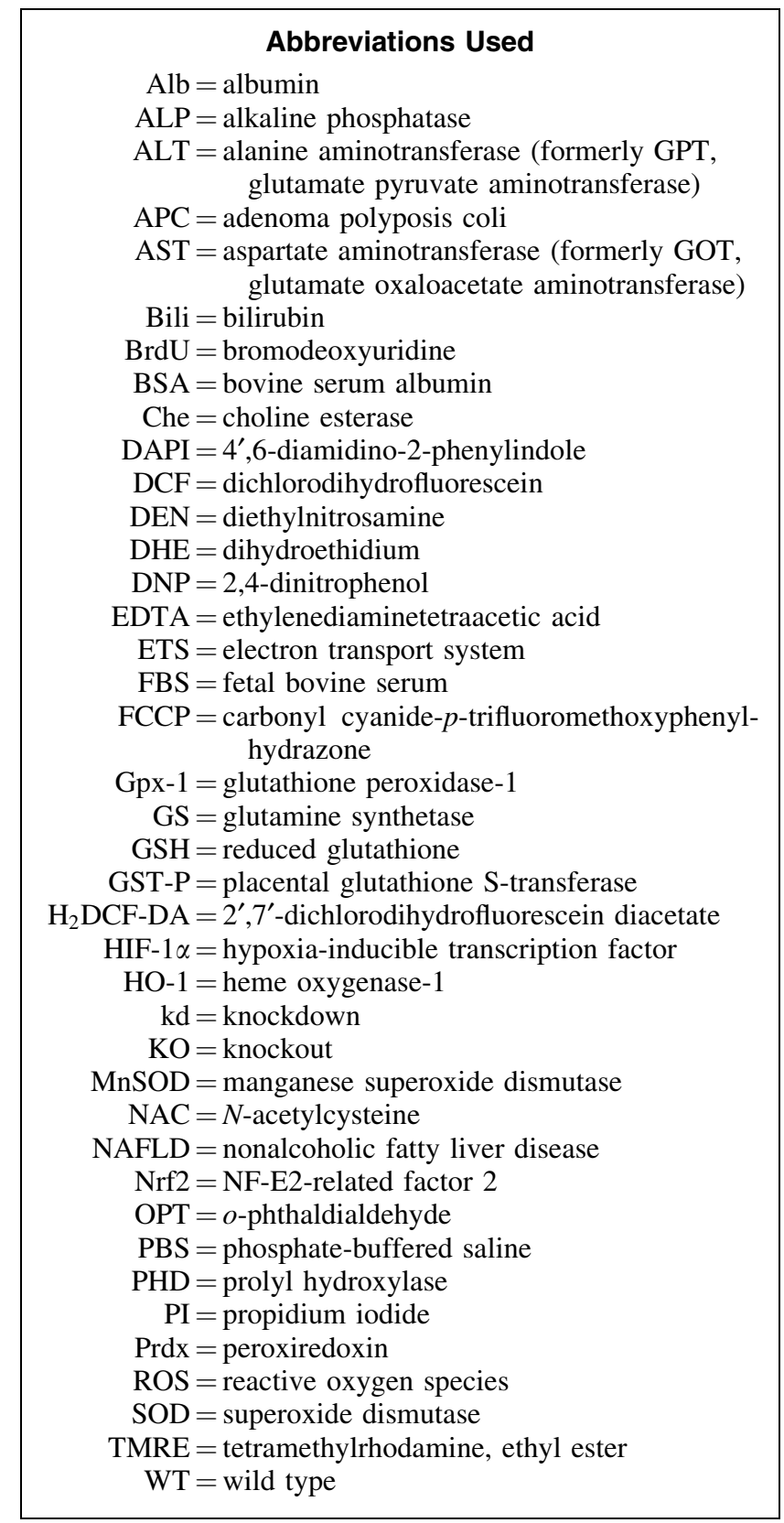

